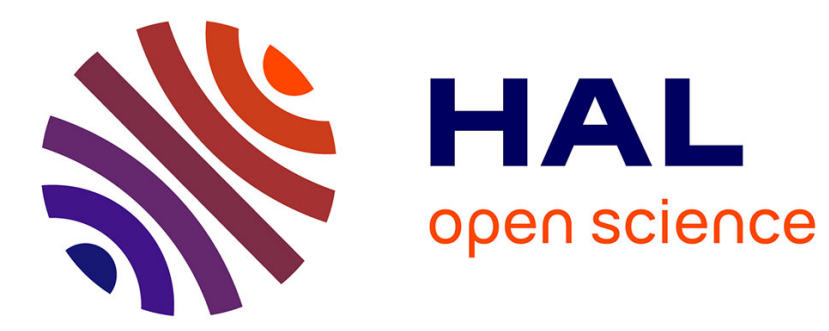

\title{
Experimental and numerical investigations of a 2D aeroelastic arifoil encountering a gust in transonic conditions
}

\author{
Fabien Huvelin, Arnaud Lepage, Sylvie Dequand
}

\section{To cite this version:}

Fabien Huvelin, Arnaud Lepage, Sylvie Dequand. Experimental and numerical investigations of a 2D aeroelastic arifoil encountering a gust in transonic conditions. CEAS Aeronautical Journal, In press, 10.1007/s13272-018-00358-x . hal-02027968

\section{HAL Id: hal-02027968 \\ https://hal.science/hal-02027968}

Submitted on 22 Feb 2019

HAL is a multi-disciplinary open access archive for the deposit and dissemination of scientific research documents, whether they are published or not. The documents may come from teaching and research institutions in France or abroad, or from public or private research centers.
L'archive ouverte pluridisciplinaire HAL, est destinée au dépôt et à la diffusion de documents scientifiques de niveau recherche, publiés ou non, émanant des établissements d'enseignement et de recherche français ou étrangers, des laboratoires publics ou privés. 


\title{
EXPERIMENTAL AND NUMERICAL INVESTIGATIONS OF A 2D AEROELASTIC AIRFOIL ENCOUNTERING A GUST IN TRANSONIC CONDITIONS
}

\author{
Fabien HUVELIN ${ }^{1}$, Arnaud LEPAGE, Sylvie DEQUAND \\ ONERA-The French Aerospace Lab \\ Aerodynamics, Aeroelasticity, Acoustics Department \\ Châtillon, 92320 FRANCE
}

KEYWORDS: Aeroelasticity, Wind Tunnel Test, CFD, Gust response, Unsteady coupled simulations

\section{ABSTRACT:}

In order to make substantial progress in reducing the environmental impact of aircraft, a key technology is the reduction of aircraft weight. This challenge requires the development and the assessment of new technologies and methodologies of load prediction and control. To achieve the investigation of the specific case of gust load, ONERA defined a dedicated research program based on both wind tunnel test campaigns and high fidelity simulations.

To reach the experimental objectives, a set-up was designed, manufactured and implemented within the ONERA S3Ch transonic wind tunnel facility. The first component, called gust generator, consists of two oscillating airfoils installed upstream of the wind tunnel test section and allows to produce air flow deflections. The second component, the test model, is a two degrees-of-freedom aeroelastic model of a supercritical airfoil. A test campaign has been performed leading to the generation of databases for high fidelity tools validation.

These databases have been used in order to assess the capabilities of the elsA code (ONERAAirbus-Safran property) using its aeroelastic module and a gust model based on the Field Velocity Method. A validation process has been defined in order to move from experimental results obtained in the wind tunnel with wall boundaries to industrial modeling computed with farfield boundaries. The full process was applied to a transonic case with sine gust excitation signals.

\section{ACKNOWLEDGEMENT}

A part of the research leading to these results has received funding from the European Union's Seventh Framework Program (FP7/2007-2013) for the Clean Sky Joint Technology Initiative under grant agreement CSJU-GAM-SFWA-2008-001.

The numerical studies presented in this paper have been partially funded by Airbus, Safran, and ONERA which are co-owners of the software elsA.

\section{INTRODUCTION}

The aircraft load analysis leads to perform a large number of aerodynamic and aeroelastic simulations. Especially, the aircraft has to be designed to withstand loads resulting from gusts. Unsteady gust analyses rely usually on linear techniques in frequency domain, based on simple Doublet Lattice Methods (DLM) for the aerodynamic flow prediction [1], [2]. These techniques are valid for subsonic flows, but could sometimes be not accurate enough to get

\footnotetext{
${ }^{1}$ Corresponding author : fabien.huvelin@onera.fr, Tel : +33 146734635
} 
realistic responses in the transonic regime, characterized by strong nonlinearities such as shocks and flow separation. Different approaches have been developed in order to simulate the gust response with Computational Fluid Dynamics (CFD) tools [3], [4]. ONERA has implemented in the elsA software the capability to compute high fidelity aeroelastic gust responses, directly in time-domain, for different discrete gust shapes [5]. The objective is to complement the classical aircraft manufacturer's tools during the critical response investigation phase by computing steady and unsteady aerodynamics with high fidelity tools (CFD) for a reduced number of critical configurations.

It is therefore required to have relevant experimental data to validate the models and tools for load prediction that will serve to design innovative approaches and to prove the efficiency of load alleviation methodologies. In the academic or industrial research area, there are few works conducted on the experimental investigation of gust in wind tunnel, especially for the transonic regime. Studies have been performed in low speed regime based on various mechanisms for creating an oscillating flow in a wind tunnel, as for example a rotating slotted cylinder [6] or [7] and oscillating airfoils [8]. In the transonic speed range, very few wind tunnel experiments can be identified: concepts based on oscillating vanes [9] or using a single pitching airfoil [10] have been recently built in transonic wind tunnel environments. But considering these studies, there is still a lot of work to perform in order to improve the understanding of the physical phenomena involved in fluid structure interaction with a gust perturbation and therefore to improve the definition of gust load alleviation strategies.

To achieve the experimental investigation, ONERA defined a research tool for gust load investigation in Wind Tunnel Test (WTT) conditions within the key objectives:

- to improve the understanding of a large scope of unsteady physical phenomena induced by gust with sensitivity tests relative to the Mach number (from subsonic at 0.3 to transonic at 0.73 ), the gust frequency (from $20 \mathrm{~Hz}$ to $80 \mathrm{~Hz}$ ), the gust amplitude (up to $+/-1^{\circ}$ ) for aerodynamic and aeroelastic configurations;

- to generate a comprehensive and relevant experimental databases for the validation of methodologies and numerical simulation such as CFD tools.

This research tool is developed using high fidelity numerical computations for a mutual benefit. On one hand, the elsA CFD code (ONERA-Airbus-Safran property) using its aeroelastic module assesses different gust generator concepts. On the other hand, the experimental results are used for gust response validation of the elsA code.

\section{NUMERICAL TOOLS}

\subsection{CFD/CSM numerical tool}

The high fidelity simulation tool developed at ONERA for aeroelastic applications is based on the elsA CFD solver (ONERA-Airbus-Safran property) for the flow computation. A general framework has been developed in the aeroelastic module of elsA over the last decade, giving access in a unified formulation of several types of aeroelastic simulations, while minimizing the impact on the flow solver. The motivation of these developments, detailed in [11], [12], [13] is to provide a numerical tool for the prediction of various aeroelastic phenomena such as flutter or limit cycle oscillations and aerodynamic phenomena involving complex flows including shocks, vortex flow, and flow separation.

\subsection{Fluid-structure coupling with a modal approach}

\section{Governing equations of the aerodynamics}


A full detailed overview of the flow solver development can be found in [14], [15]. For an aeroelastic problem, an Arbitrary Lagrangian Euler (ALE) formulation is used. The 3 formulation adds a grid velocity $\left(\boldsymbol{v}_{\text {grid }}\right)$ in the standard Eulerian formulation allowing to 4 switch from the Eulerian formulation (fixed grid, $\boldsymbol{v}_{\text {grid }}=0$ ) to the lagrangian formulation 5 (moving grid, $\boldsymbol{v}=\boldsymbol{v}_{\text {grid }}$ ).

$$
\begin{gathered}
\text { Mass: }\left.\frac{\partial}{\partial t}\right|_{\chi} \int_{\Omega} \rho d V+\int_{\partial \Omega} \rho \boldsymbol{c} \cdot \boldsymbol{n} d S=0 \\
\text { Momentum: }\left.\frac{\partial}{\partial t}\right|_{\chi} \int_{\Omega} \rho \boldsymbol{v} d V+\int_{\partial \Omega} \rho \boldsymbol{v} \boldsymbol{c} \cdot \boldsymbol{n} d S=\int_{\Omega}(\nabla \cdot \boldsymbol{\sigma}+\rho \boldsymbol{b}) d V \\
\text { Energy: }\left.\frac{\partial}{\partial t}\right|_{\chi} \int_{\Omega} \rho E d V+\int_{\partial \Omega} \rho E \boldsymbol{c} \cdot \boldsymbol{n} d S=\int_{\Omega}(\nabla \cdot(\boldsymbol{\sigma} \cdot \boldsymbol{v})+\boldsymbol{v} \cdot \rho \boldsymbol{b}) d V
\end{gathered}
$$

where, $\mathrm{t}$ is the time, $\chi$ the reference coordinate, $\Omega$ an arbitrary volume with a surface boundary $\partial \Omega, \rho$ the density, $\boldsymbol{c}$ the convective velocity, $\boldsymbol{n}$ the normal to the boundary surface, $\rho \boldsymbol{v}$ the momentum, $\rho E$ the specific total energy, $\boldsymbol{\sigma}$ the Cauchy tensor, $\boldsymbol{v}$ the material velocity and $\boldsymbol{b}$ the specific body force vector. The convective velocity is expressed with the material velocity and the grid velocity:

$$
\mathbf{c}(\chi, t)=\boldsymbol{v}(\chi, t)-\boldsymbol{v}_{\text {grid }}(\chi, t)
$$

The unsteady aeroelastic simulations are performed using the dual time-stepping technique, allowing large physical time-steps and mesh and grid velocity updates from the structural solver during the iterative process.

\section{Gust modelling in flow solver}

There are several possibilities in order to implement a gust perturbation in CFD codes. One way consists in introducing the gust velocity as a disturbance on the farfield boundary conditions of the computational domain [16]. The gust fluctuation is then propagated into the domain by solving the Navier-Stockes equations. The main advantage of this approach is to take into account the effect of the gust on the aircraft, but also the reverse effect of the aircraft on the gust. The main disadvantage of such modeling is the required grid refinement in order to propagate the gust from the upstream boundary to the structural model without any numerical dissipation schemes.

An alternative approach is to use the so-called Field Velocity Method (FVM) suggested by Sitaraman et al [17] which has been implemented in elsA [5], [18]. A prescribed gust velocity field ( $\left.\boldsymbol{v}_{\text {gust }}\right)$, depending on both space and time, is added to the grid velocity in each cell of the aerodynamic grid:

$$
\boldsymbol{v}_{\text {grid }}(\chi, t) \rightarrow \boldsymbol{v}_{\text {grid }}(\chi, t)+\boldsymbol{v}_{\text {gust }}(\chi, t)
$$

This modeling avoids the numerical dissipation due to the grid refinement but does not take into account the reverse effect of the aircraft on the gust [16], [19]. The absence of the aircraft disturbance on the gust compromise the flow physics for small gust length (less than 5 chord) and has a minor impact on large gust length (more than 30 chords) comparing to a split velocity method [20].

\section{Governing equations for the structure}


1 The elsA aeroelastic solver uses a modal approach to compute structural displacements and

2 velocities. The governing equation in physical coordinates is given by:

$$
\left[M_{S}\right] \ddot{\boldsymbol{u}}(X, t)+\left[D_{S}\right] \dot{\boldsymbol{u}}(X, t)+\left[K_{S}\right] \boldsymbol{u}(X, t)=\boldsymbol{f}(X, t)
$$

where $M_{s}, D_{s}$ and $K_{s}$ are the structural mass, damping and stiffness matrices, respectively, $\boldsymbol{u}(X, t)$ the structural displacement vector depending on space $X$ and time $t$, and $\boldsymbol{f}(X, t)$ the force vector such as the aerodynamic forces calculated by elsA on the fluid-structure interface. The modal analysis leads to describe the structural displacement as follows:

$$
\boldsymbol{u}(X, t)=\sum_{i=1}^{N} q_{i}(t) \boldsymbol{\phi}_{i}(X)=[\phi] \boldsymbol{q}(t)
$$

where $N$ denotes the number of modes which are retained for the analysis, $\boldsymbol{\phi}_{i}$ are the mode shapes, and $q_{i}$ are the modal coordinates. By means of a projection of equation (6) on the modal basis, the structural system in modal form is given by:

$$
[\phi]^{T}\left[M_{S}\right][\phi] \ddot{\boldsymbol{q}}(t)+[\phi]^{T}\left[D_{s}\right][\phi] \dot{\boldsymbol{q}}(t)+[\phi]^{T}\left[M_{S}\right][\phi] \boldsymbol{q}(t)=[\phi]^{T} \boldsymbol{f}(X, t)
$$

If $\boldsymbol{f}(X, t)$ corresponds to the aerodynamic forces, gaf $=[\phi]^{T} \boldsymbol{f}(X, t)$ is called generalized aerodynamic forces (GAF). For the elsA aeroelastic solver, the modes shape, modal mass and modal stiffness properties are usually derived from a finite-element solver in a pre-processing step. Usually, the damping on each mode $i$ is imposed with a damping ratio $\varsigma_{i}$ as follows:

$$
d_{i}=2 \pi f_{i} m_{i} S_{i}
$$

with $f_{i}=\frac{1}{2 \pi} \sqrt{\frac{k_{i}}{m_{i}}}$ the natural frequency for the mode $i$.

The structural equations are solved in the time domain using a Newmark method.

\section{Data interpolation}

Structural displacements must be interpolated onto the aerodynamic grid and reciprocally aerodynamic forces must be interpolated onto the structural grid. A volume spline method [21] is used in order to match the mode shapes onto the aerodynamic grid in a pre-processing step :

$$
\left[\phi^{f}\right]=[H][\phi]
$$

During unsteady simulations, displacements are obtained from a linear combination of the generalized coordinates and mode shapes expressed on the aerodynamic grid. The generalized aerodynamic forces on each mode are computed by the dot product of the aerodynamic forces with the mode shapes expressed on the aerodynamic grid.

$$
\begin{aligned}
\boldsymbol{u}_{\boldsymbol{f}}(X, t) & =\sum_{i=1}^{N} q_{i}(t) \boldsymbol{\phi}_{\boldsymbol{i}}^{f}(X) \\
g a f_{i} & =\boldsymbol{\phi}_{\boldsymbol{i}}^{f}(X) \cdot \boldsymbol{f}(X, t)
\end{aligned}
$$

\section{Mesh deformation}

A mixed analytical/transfinite interpolation technique [22] is used to propagate the aerodynamic surface displacements in the surrounding volume aerodynamic mesh. As the CFD code uses a structured mesh, the displacement of an internal block boundary node P is computed automatically from the displacements of all "wall nodes” $\mathrm{M}$ from: 


$$
\delta P=\frac{\sum_{M \epsilon \text { Wall }} \frac{\delta M}{P M}}{\eta \sum_{M \epsilon \text { Wall }} \frac{\delta M}{P M}}
$$

1 The coefficient $\eta$ embodies a damping function going to 1 when $P$ is close to the wall 2 boundaries. This result does not depend on the matching or overlapping character of the 3 internal boundary, and the technique is then directly operational without any change in the 4 case of overset grids. The internal nodes of each block are then solved by a transfinite 5 interpolation.

As a modal approach is used for unsteady coupling, individual modal mesh deformations $\Delta \Omega_{i}$ are first computed at the beginning of the coupled simulation, using the analytical/transfinite interpolation technique. The instantaneous mesh deformation $\Omega^{n+1}$ of the new physical time $\mathrm{n}+1$ is then computed as a linear combination of these individual "modal" mesh deformations combined to modal coordinates of the structural dynamic system:

$$
\Omega^{n+1}=\Omega^{n}+\sum_{i=1}^{N} q_{i}^{n+1} \Delta \Omega_{i}
$$

\section{Coupling strategy}

The fluid-structure coupling methodology aims to solve a problem at the fluid-structure

interface:

$$
\left\{\begin{array}{c}
\boldsymbol{v}_{\boldsymbol{F}}(\chi, t)=\dot{\boldsymbol{u}}_{\boldsymbol{S}}(X, t) \\
\int_{\partial \Omega} \boldsymbol{\sigma}_{\boldsymbol{F}} \cdot \boldsymbol{n} d S=\boldsymbol{f}_{\boldsymbol{S}}{ }^{\boldsymbol{a e r o}}(X, t)
\end{array} \text { on } \partial \Omega_{F / S}\right.
$$

The coupling procedure may be viewed as a fixed-point iteration method for the displacements at each time-step. For a given number of sub-iteration during a time step, the following steps are performed for each sub-iteration $\mathrm{k}$ (Figure 1):

1. Marching of the flow solution

2. Computation of the generalized aerodynamic forces $g a f_{i}$ for each mode

3. Computation of the generalized coordinates $q_{i}$ by solving the modal system;

4. Computation of the displacements on the aerodynamic surface grid $\boldsymbol{u}_{f}(X, t)$;

5. Deformation of the aerodynamic grid $\Omega^{n+1, k}$.
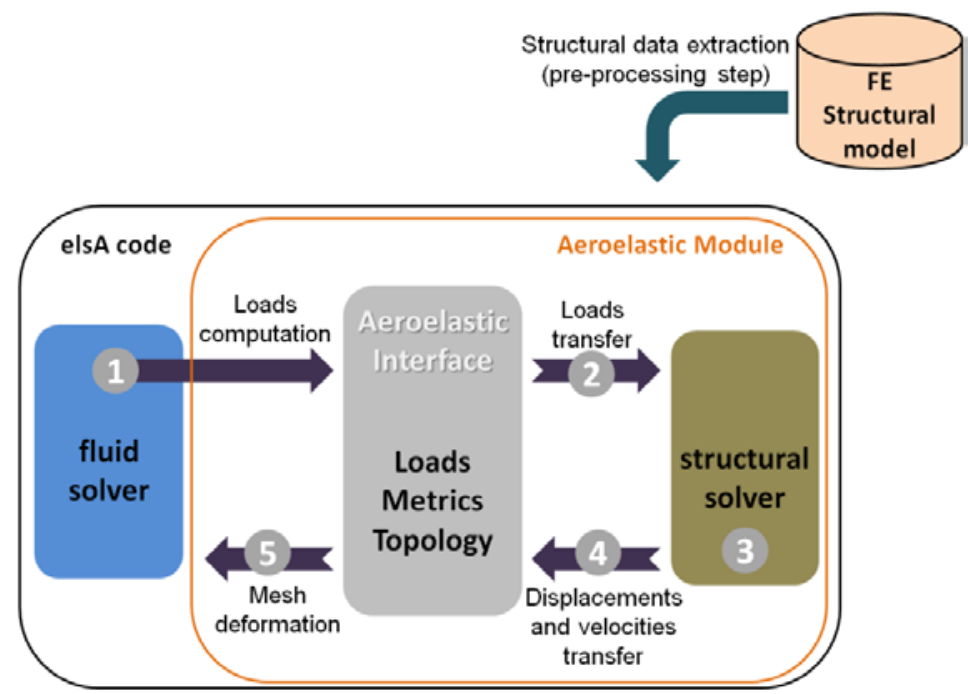

Figure 1: Aeroelastic optional module of elsA for aeroelastic simulations 


\section{EXPERIMENTAL ROADMAP}

\subsection{ONERA S3Ch Wind Tunnel}

Tests have been performed in the research ONERA S3Ch wind tunnel located at the ONERA Meudon Center (Figure 2). This closed return wind tunnel is a transonic continuous run facility with a $0.8 \mathrm{~m} \times 0.8 \mathrm{~m}$ square test section of $2.2 \mathrm{~m}$ length. It covers a Mach number range from 0.3 to 1.2 and operates at atmospheric stagnation pressure and temperature. The top and bottom walls of the test section can be either rigid walls or deformable adaptive walls. In the latter case, the wall displacements are estimated in order to adapt the steady flow in the model area by minimizing the wall interferences.

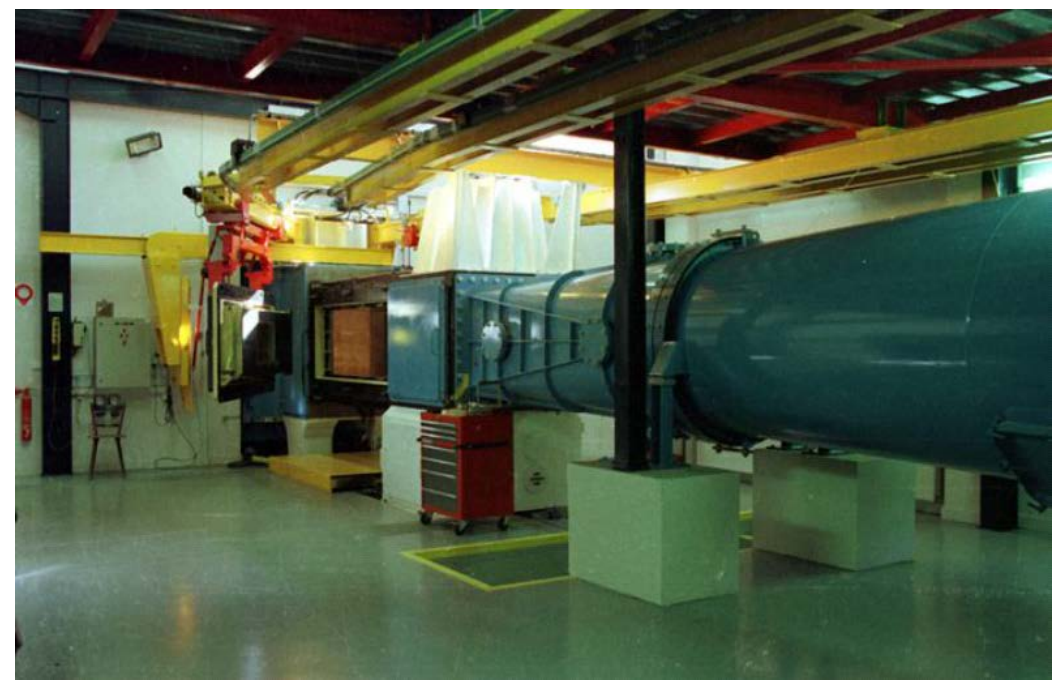

Figure 2- ONERA S3Ch wind tunnel located at the ONERA Meudon Center

\subsection{Gust generation in WT environment}

\subsubsection{The gust generator concept}

The purpose of this device is to develop an experimental tool in order to generate relevant perturbations (gust load) for wind tunnel conditions from subsonic to transonic conditions. The concept of the gust generator is composed of two movable 2D wings fixed on the lateral walls of the wind tunnel. The gust generator is located upstream the WTT section and its functioning is based on unsteady synchronous pitch motions of the two airfoils. This architecture allows to generate a gust field downstream the test section.

The technical definition of the gust generator is based on CFD results. Unsteady RANS calculations are carried out using the elsA software and its aeroelastic functionalities. The gust generator motion is solved using chimera approach (meshes with overlapped areas, see Figure 3) with the fluid-structure coupling strategy defined in Section 2.2. The structural solver is replaced by a harmonic function describing the gust generator motion and given directly the generalized coordinates. Thus, only one sub-iteration is performed for the fluidstructure coupling algorithm.

The representativeness of the simulations results is improved by taking into account the real geometry of the WT (Figure 3). In order to limit the mesh size, wall-slip boundary conditions are imposed on the upper and lower walls of the wind tunnel and adiabatic conditions of adherent wall are applied on both airfoils. Numerical parametric studies investigate the influence of the different criteria below mentionned on the performances and possibilities in terms of gust generation: 
- Effect of geometric parameters (airfoil type, chord, distance between the two wings, longitudinal position of wings);

- Influence of actuating parameters (frequency and amplitude of the pitch motion);

- Effect of aerodynamic conditions (angle of attack, Mach number).

The criterion in order to assess the parameter effect on the performances is the ratio between vertical $\left(V_{Z}(t)=V_{Z}^{\text {mean }}+V_{Z}^{\text {deviation }}(t)\right)$ and longitudinal $\left(V_{X}(t)=V_{X}^{\text {mean }}+V_{X}^{\text {deviation }}(t)\right)$ velocities called "gust angle":

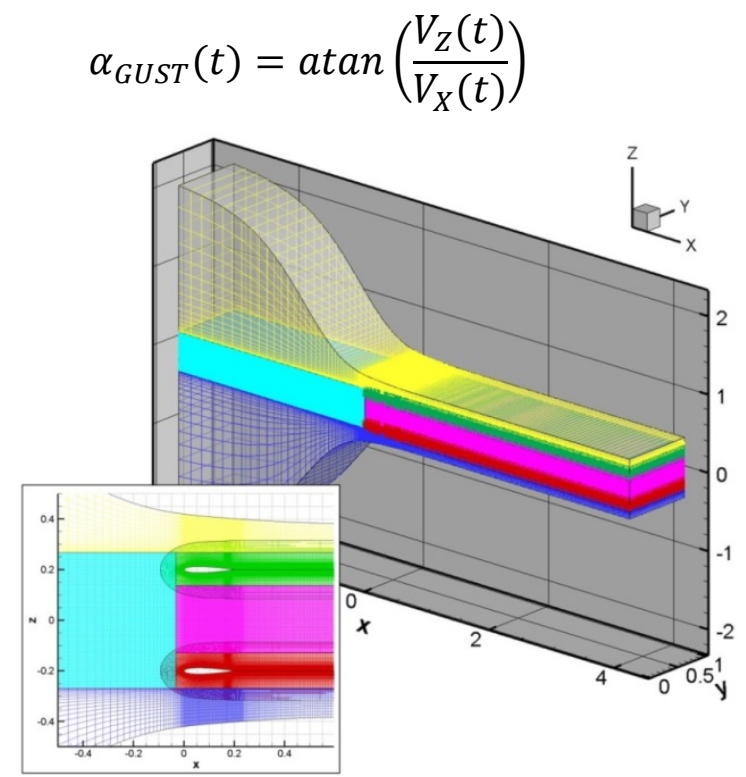

Figure 3- 3D view and detail of computational domain with WT walls

8 Typical simulation results with the walls interferences are presented in Figure 4 through the 9 visualization of the gust angle distributions for a sinusoidal motion of the gust generator. The spatial distribution of gust angle on the left part presents the generated gust field with a 11 periodic characteristic based on the wave length $\lambda=\frac{\omega}{U_{\infty}}$ where $\omega$ is the actuating pulsation of 12 the gust generator wings and $U_{\infty}$ is the flow velocity. Near wind tunnel walls, the gust field is clearly attenuated by the walls interference. The wake effect is noticeable in the area downstream each airfoil. The obtained gust amplitudes are relatively homogeneous in an area around the centerline of the wind tunnel section (left and right graphic of Figure 4) for a reduced frequency $k=\frac{\omega . c}{\mathrm{U}_{\infty}}=0.3$ where $\mathrm{c}$ is the airfoil chord. 

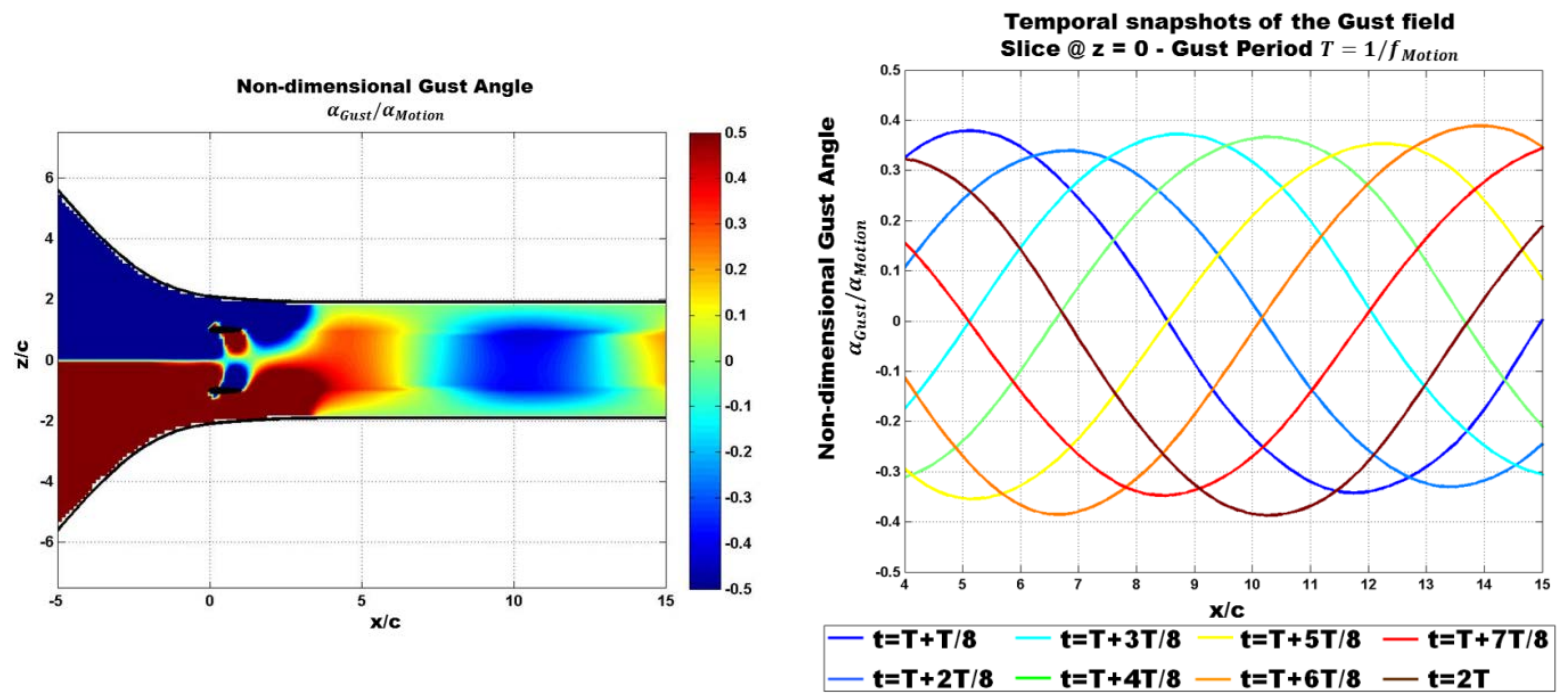

Figure 4- Spatial distribution of the gust angle in WT section versus X-Z Locations (left) and longitudinal distribution at $\mathrm{Z}=0$ of the gust angle in WT section versus $\mathrm{X}$ for different time snapshots (right)

\subsubsection{Qualification of the gust generator}

The experimental qualification of the gust generator is performed in two steps. First, a specific mechanical frame is used to arrange the two wings in a horizontal arrangement in a test rig with similar boundary conditions like the ones of the wind tunnel. Unsteady motions tests allow assessing the achievable frequency and amplitude ranges of the gust generator.

Then, a campaign in the ONERA S3Ch Wind Tunnel is carried out in order to estimate the gust field for a given frequency and amplitude ranges (Table 1).

\begin{tabular}{|c|c|c|c|}
\hline Mach number & Reynolds number & Actuator frequency range & Actuator amplitude range \\
\hline 0.30 & $1.610^{6}$ & {$[20 \mathrm{hz} ; 80 \mathrm{~Hz}]$} & {$\left[0.5^{\circ} ; 5.0^{\circ}\right]$} \\
\hline 0.73 & $3.310^{6}$ & {$[20 \mathrm{hz} ; 80 \mathrm{~Hz}]$} & {$\left[0.5^{\circ} ; 3.0^{\circ}\right]$} \\
\hline
\end{tabular}

Table 1 - Experimental test matrix for gust generator qualification

Two measurements devices are used to qualify the flow:

- An unsteady clinometric probe especially designed and manufactured for these tests. This "gust sensor" allows to investigate the unsteady flow field downstream in the test section by recording a real time signals of the gust angle. An overview of this experimental set-up is shown in Figure 5.

- A two components phase averaged Particle Image Velocimetry (PIV) system composed of a double pulse laser and a high resolution camera. The laser is installed below the test section such as illuminating a vertical plane $(\mathrm{Oxz})$ aligned with the flow (Figure 6). The time resolution is obtained through phase averaging locked to the airfoil motion [23]. 


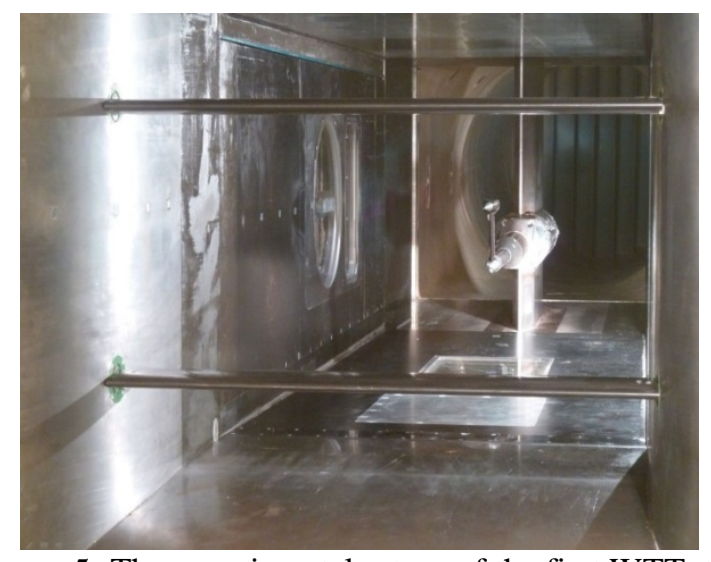

Figure 5- The experimental set-up of the first WTT: the gust generator (foreground) and the unsteady clinometric probe (background)

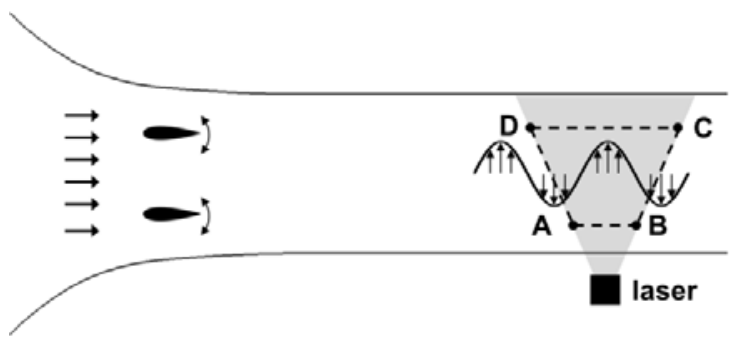

Figure 6- Illustration of the PIV setup

1 The results and analyses indicate that the gust generator allows to generate a cylindrical gust field in wind tunnel environment in a reproducible way with significant gust amplitudes. Typical results are shown in Figure 7 . The left graphic shows the dimensionless time (ratio of the time multiplied by the excitation frequency) evolution of the gust angle measured by the clinometric probe. It demonstrates that a sinusoidal command induces a sinusoidal unsteady motion of the two wings generating therefore a sinusoidal gust. For this example at Mach number 0.73 , an unsteady actuation of the wings of $+/ 2^{\circ}$ in amplitude at a frequency $f_{g}=$ $40 \mathrm{~Hz}$ induces a gust amplitude of about $+/-0.4^{\circ}$ flow deviations with respect to the steady flow. A frequency analysis is given in the right graphic of Figure 7 and shows the principal component of the gust field against the ratio of the frequency divided by the excitation frequency. Higher harmonics could be identified but with a lower order of magnitude and may result from on aerodynamic phenomena such as the vortex emission of the airfoil or on weak non-linear structural behavior of the gust generator setup.
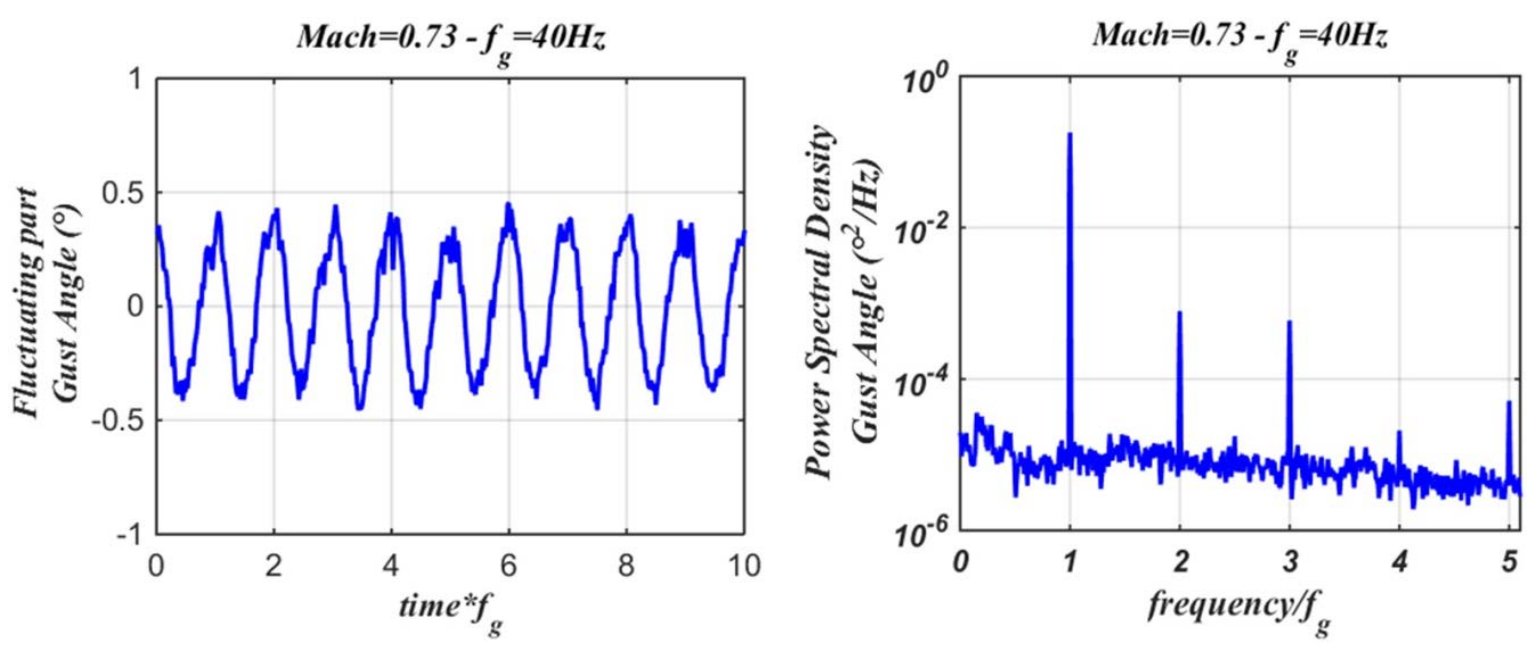

Figure 7- Temporal evolution of Gust Sensor Signal (left) and frequency analysis (Power Spectral Density) of the Gust Sensor Signal (right)

In addition to probe data, PIV measurements allow to complementarily qualify the unsteady gust field. Figure 8 shows the spatio-temporal reconstructions of the longitudinal and vertical velocity components for the similar tests point presented in Figure 7. Each frame represents the flow variations over one wavelength of the gust. 

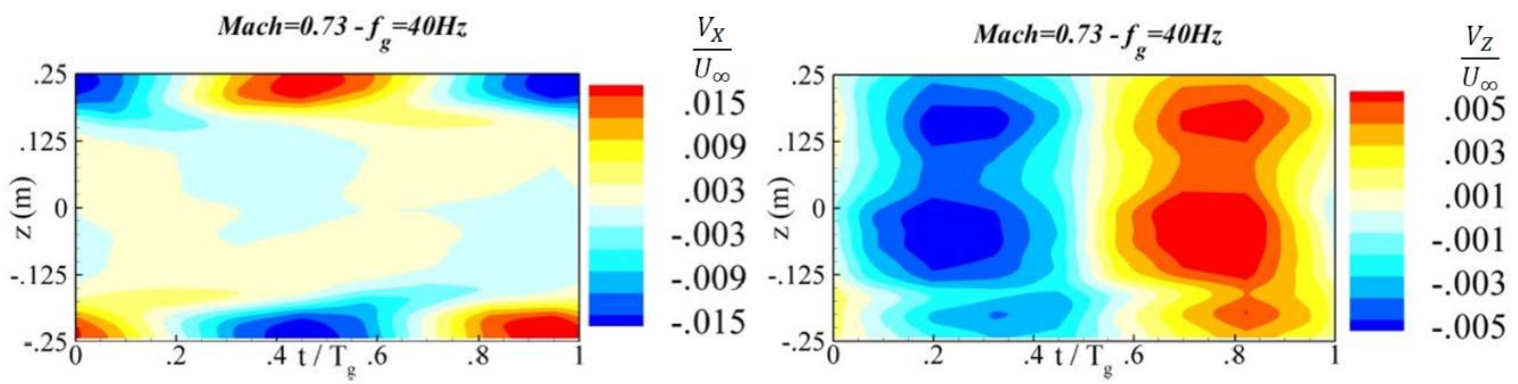

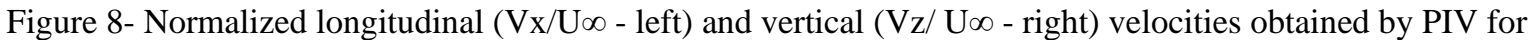
Mach 0.73 and a frequency generation of $\mathrm{fg}=40 \mathrm{~Hz}$ - Time line normalized by the gust period $\mathrm{Tg}=1 / \mathrm{fg}-\mathrm{Spatial}$ measurements at $\mathrm{X}=1.2 \mathrm{~m}$ (probe location)

The influence of the walls and the effects of the wings wake $(Z=+/-0.2 m)$ are clearly emphasized with strong variations of the velocity longitudinal components while small scale disturbances are observed in central area $(\mathrm{Z} \sim 0 \mathrm{~m})$. The vertical velocity field demonstrates clearly an alternating upward and downward flow, i.e. an alternating positive and negative flow angle, as function of time. The analysis along the vertical axis indicates a variation of homogeneity which is still nevertheless moderated in the center area.

\subsection{Aeroelastic model}

\subsubsection{Airfoil and mounting system}

In order to investigate the effects of impacting gusts on a model, a bidimensional airfoil is selected and based on the OAT15A profile ([24] - [26]) (supercritical airfoil with a design point at Mach $\mathrm{M}=0.73$ and a thickness to chord ratio of $12.3 \%$ ). The model has a $250 \mathrm{~mm}$ chord and a 3.2 aspect ratio.

During the design phase, on one hand, the objective was to fix the airfoil in the section as rigid as possible in order to investigate the $2 \mathrm{D}$ aerodynamic characteristics around the model. On the other hand, the boundary conditions of the model aim at providing the behavior of a classical two degrees-of-freedom (dof) aeroelastic model, i.e. a 2D model with a pitch and heave dof. Common heave-pitch model design approaches are reported in the literature and are devoted most of the time to flutter phenomena purposes. One of the most well-known is the Pitch And Plunge Apparatus (PAPA) developed at NASA [25] and provides the two dof needed for classical flutter. This device consists of a fixed plate attached to the tunnel sidewall turntable, a set of fixed-end rods and a moving plate. The mount system can be dynamically tuned by the addition of masses attached to the moving plate to adjust the model center of gravity and the frequencies of structural modes. A preliminary design was based on a modified version of the PAPA concept and adapted to a symmetric mount system. Although the concept fully filled most of the specifications, the main disadvantages was the limited range of adjustment of the modal frequencies in order to avoid mode coupling. Therefore a novel concept has been studied for the design of a pitch-heave model. For each dof, the stiffness properties are driven by flexible beams with in addition an arrangement of bearings. The mounting system is composed of two identical mountings parts located on each test section door as shown in Figure 9. 


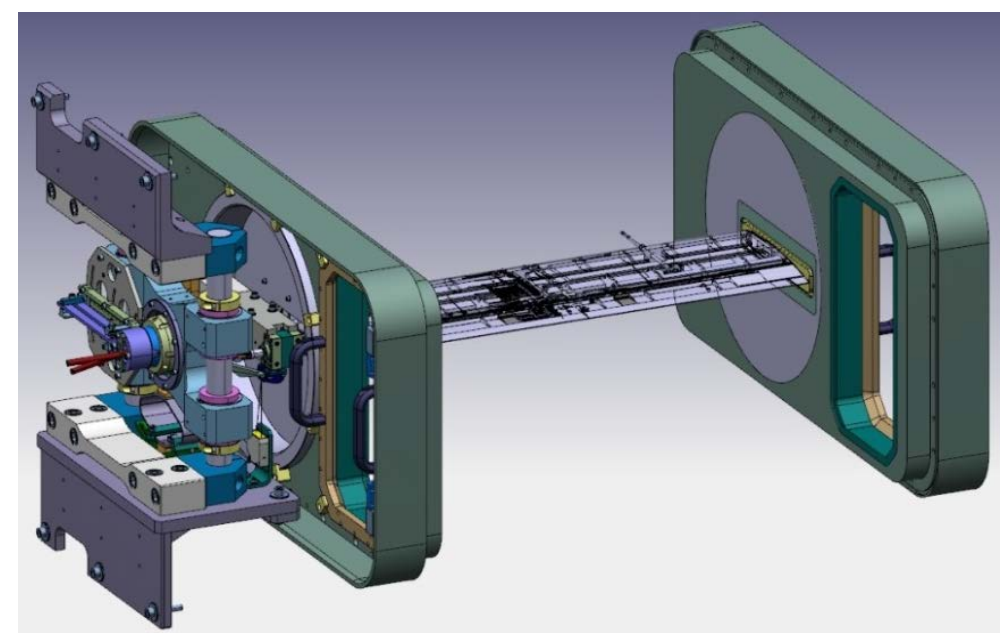

Figure 9- Overview of the 2D aeroelastic model installed in the S3 WTT section with the flexible mount system For both dof, the beam stiffnesses are optimized through Finite Element Models (FEM) in order to satisfy static loads requirements and to tune dynamics properties in the frequency range of interest. The main advantage of this mount system is that pitch and heave stiffnesses can be modified independently by adjusting the length of clamping condition of each "stiffness beam".

\subsubsection{Structural model characterization}

Before the WTT campaign, an experimental characterization of the model structural behavior is performed using a mechanical frame and a massive bracket in order to simulate the mounting conditions in the wind tunnel. The static behavior of the airfoil is analyzed with the results of different static loads. At first, the main stiffness components (i.e. the "pitch and heave stiffness beams") are characterized separately. An overview of the static tests is illustrated in Figure 10 during a progressive loading performed by adding or removing some elementary mass step by step. Typical results of the mechanical strains ( $\mu$ def) versus load (Force(N)) corresponding to each load case are plotted in Figure 11 for the "heave beams" indicating a good linearity and a weak dispersion on the static behavior of the different components.

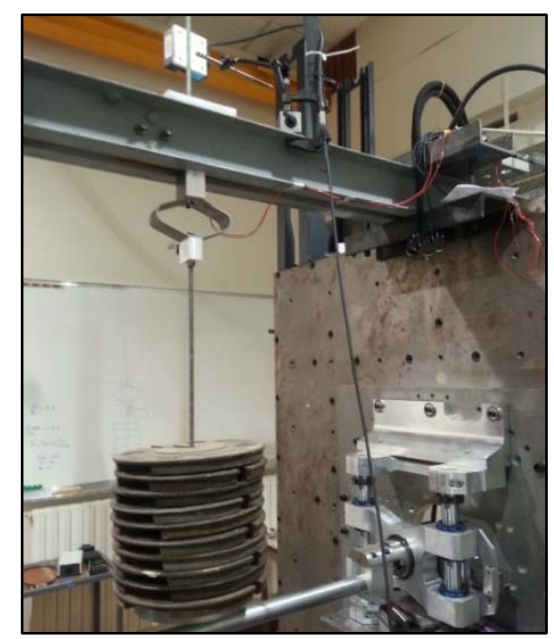

Figure 10- Static test of the "heave" beam

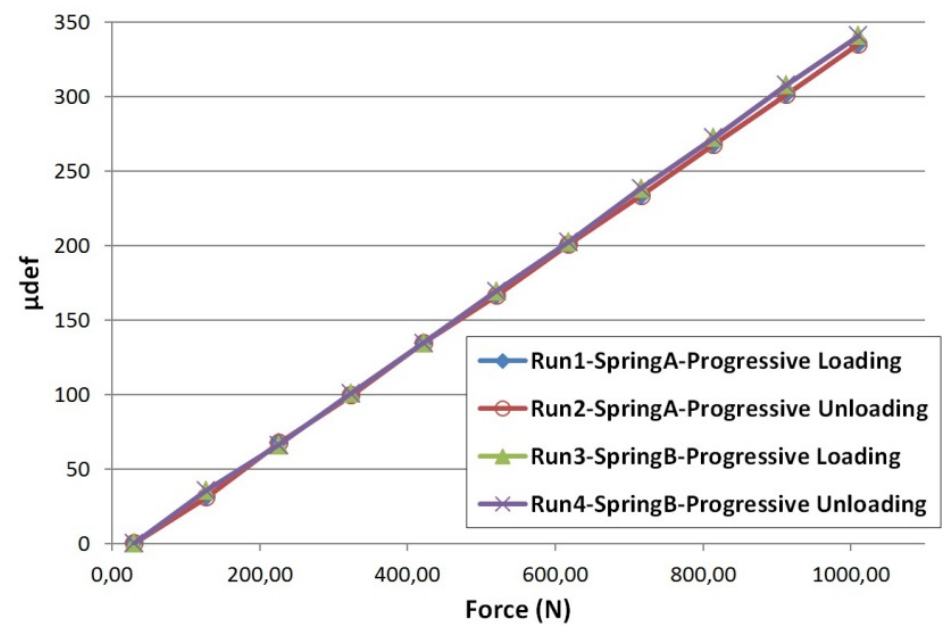

Figure 11- Strain versus force results for different load cases on the "heave" beam 
An important step is the qualification of the dynamic behavior of the model with the main objective to estimate the structural parameters (i.e. modal parameters such as eigenfrequencies, modal damping ratios, modal masses and mode shapes). A classical methodology of experimental modal analysis (Figure 12) is applied: the structural sensors responses are recorded using embedded and additional accelerometers relative to different excitation signals and locations of the dynamic shaker. Figure 13 gives an illustration of the first two identified mode shapes with their eigenfrequencies and damping ratios for a given set of tuning parameters (clamping condition).

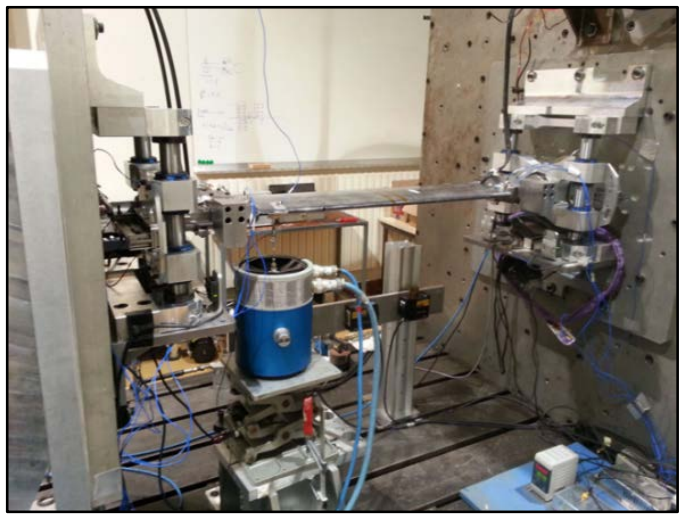

Figure 12- Test set-up for the unsteady qualification with various shaker configurations

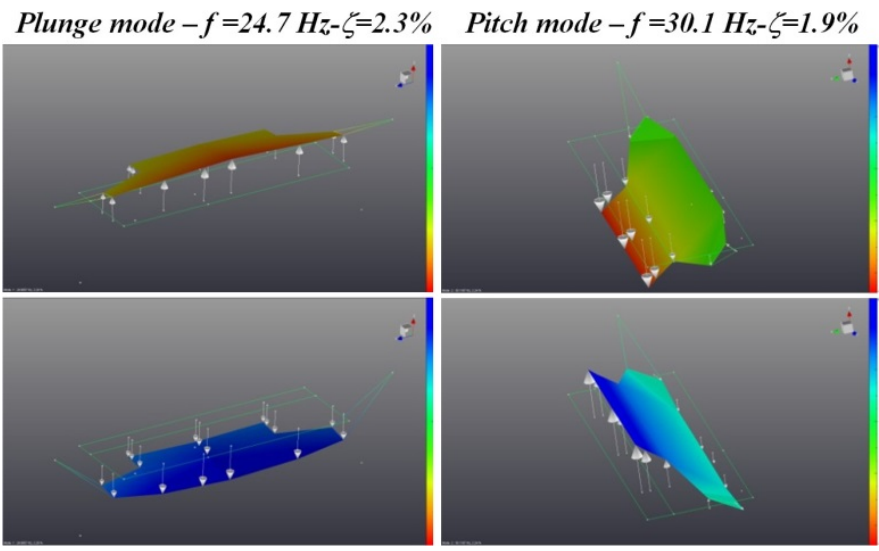

Figure 13- First two structural modes (structural modes represented for positive and negative extreme values)

The main hard point is the presence of nonlinearities in the structural dynamic behavior of the model. Dynamic tests clearly emphasize that the use of bearings results in the apparition of friction especially for the heave mode. Nevertheless, a fine analysis indicates that this non linearity follows a classical behavior: the modal frequency decreases with an increase of the force level as shown in Figure 14 with an asymptotic behavior.

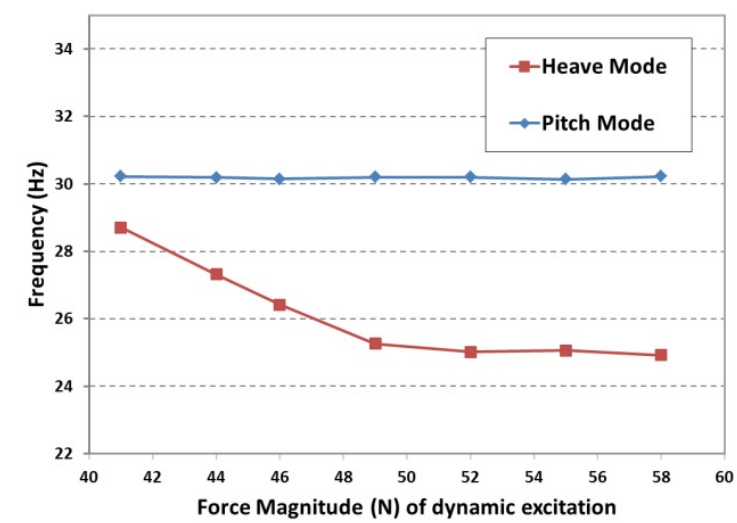

Figure 14- Impedance curves for the heave and pitch modes

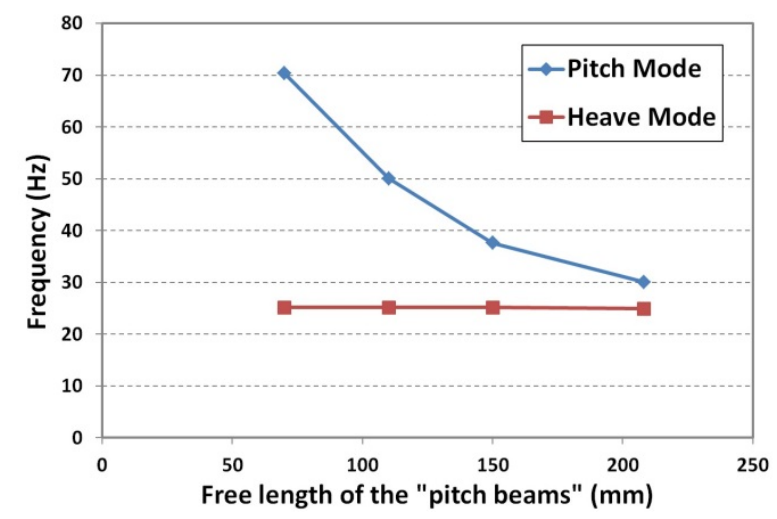

Figure 15- Influence of the clamping conditions on the pitch frequency

Regarding the modes order, the modal behavior agrees with the model specifications: the two rigid modes (i.e. the heave and pitch modes) are present in the low range of the useful bandwidth of the Gust Generator, $24.7 \mathrm{~Hz}$ and $30.1 \mathrm{~Hz}$ respectively, while the first flexible mode (i.e. the bending mode) is located at higher frequency $(77.2 \mathrm{~Hz})$. Also positive from a technical perspective, the modes are clean and uncoupled. In particular, the heave and pitch modes are mainly composed of rigid body components as expected. Moreover, the designed 2 dof mount system allows parametric variations of the modal frequencies depending on the 
1 clamping conditions of the "stiffness beams". Figure 15 exhibits the pitch frequency variation 2 as a function of the free length of the "pitch stiffness beams" without any noticeable effect on 3 the heave mode.

4 The experimental modal parameters are finally used in a flutter calculation with Doublet lattice Method to ensure the absence of any aeroelastic instability. Parametric analyses are considered for various clamping conditions and for the two Mach numbers of the experimental test matrix (Table 1).

\subsubsection{Model instrumentation}

In order to generate an experimental database for the validation of high fidelity numerical codes, different measurements techniques are selected for the WTT. The main part of the instrumentation consists of steady and unsteady pressure transducers arranged in two span stations: one steady and one unsteady pressure measurements sections. As the S3Ch wind tunnel is not equipped with external force balance, the estimation of aerodynamic forces and moments can be estimated by integrating the pressure distributions.

Additionally, the model is equipped with accelerometers mounted in three span stations in order to correctly handle the unsteady motions for both flexible and rigid conditions. The main embedded instrumentation is synthesized in Figure 16 and is composed of 44 unsteady pressure sensors (Kulite), 31 steady pressure sensors (pressure taps) and 12 accelerometers. In order to preserve the aerodynamic of the airfoil, the design of the model is performed without any cover or access on the upper and lower sides of the wing. Consequently, the whole model instrumentation is realized simultaneously with the manufacturing.

A clinometric probe used for the gust generator qualification is embedded on the airfoil. Measurements are performed $0.08 \mathrm{~m}$ ahead the leading edge.
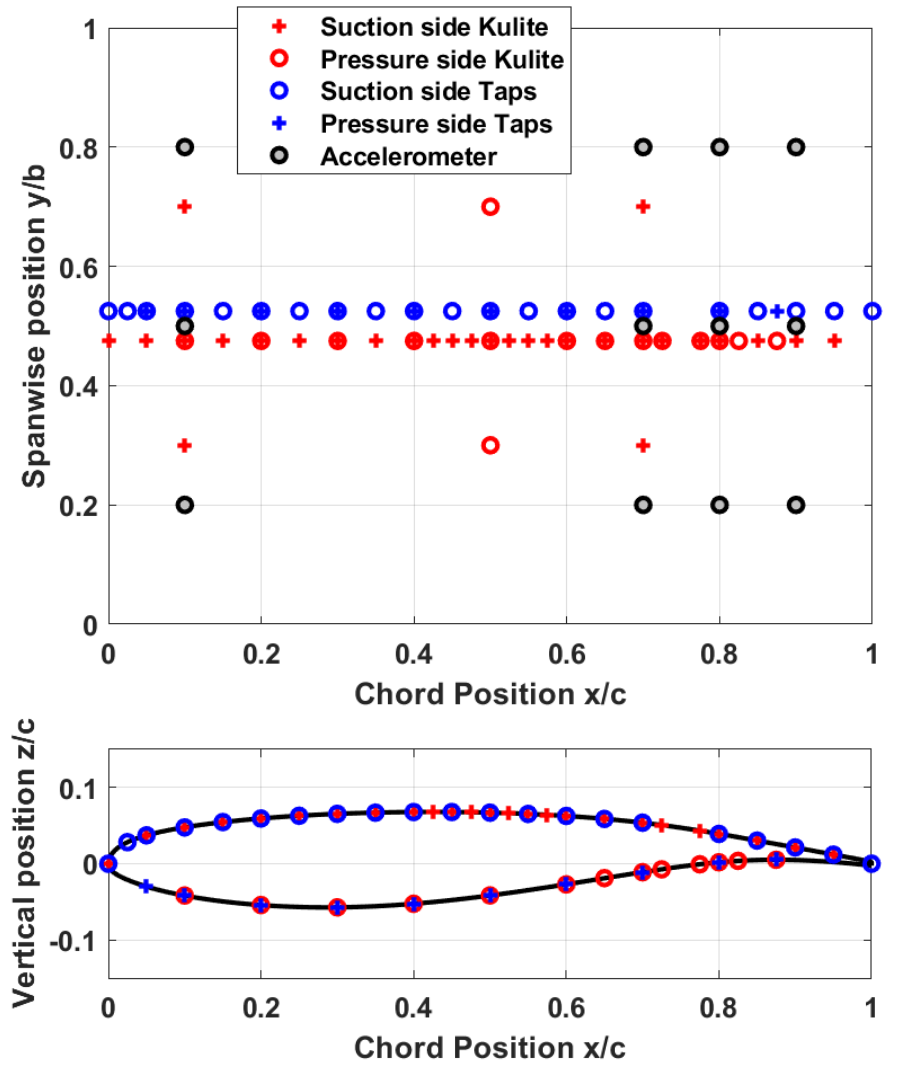

Figure 16- Locations of embedded pressure sensors and accelerometers 


\section{WTT CAMPAIGN: ANALYSIS OF THE BEHAVIOUR OF THE AEROELASTIC AIRFOIL ENCOUNTERING A GUST}

\subsection{WTT conditions and program}

The campaign in the ONERA S3Ch Wind Tunnel aims to study the response of the aeroelastic model encountering a gust. An overview of the complete experimental set-up is shown in Figure 17. In the background, the gust generator device is located in the final part on the convergent area of the wind tunnel while the wing part of the aeroelastic model is visible downstream in the test section.

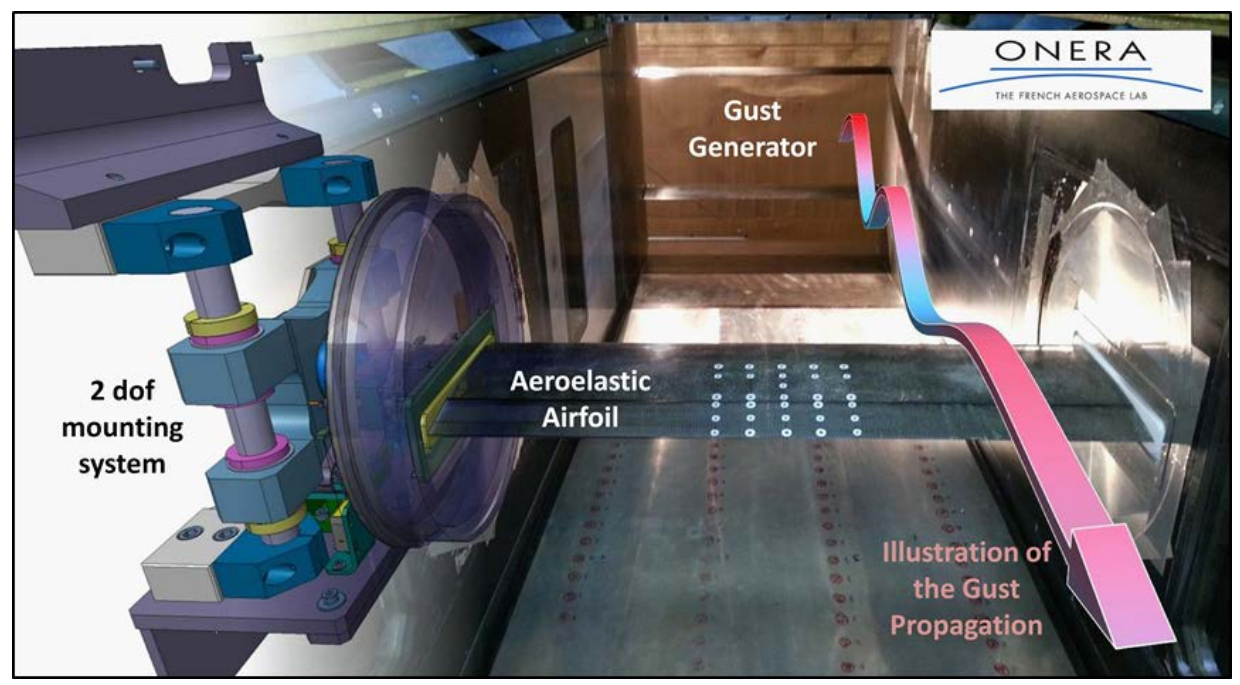

Figure 17- Complete experimental set-up for gust load investigation in the S3Ch Wind Tunnel facility

Experiments are performed using adaptive upper and lower walls. From the measured wall pressure distributions, off line calculations performed outside of the test section allow to determine the shape of the walls so that they correspond to flow streamlines. It has to be pointed out that this technique only allows to adapt the walls to the time-averaged flow. As a consequence, each test point involving a fluctuating parameter is achieved with the walls shape of the corresponding time-averaged test point. The transition is triggered at a chordwise position of $\mathrm{x} / \mathrm{c}=7 \%$ on the upper and lower surfaces with adhesive strips designed for Mach $\mathrm{M}=0.73$.

In order to correctly handle gust effects on the model, the same test matrix than for the gust qualification is performed with a specific adaption of the upper and lower wind tunnel walls to the airfoil, Mach number and angle of attack (Table 2).

\begin{tabular}{|c|c|c|c|c|c|}
\hline $\begin{array}{c}\text { Mach } \\
\text { number }\end{array}$ & $\begin{array}{c}\text { Reynolds } \\
\text { number }\end{array}$ & $\begin{array}{c}\text { Angle of } \\
\text { attack range }\end{array}$ & $\begin{array}{c}\text { Actuator } \\
\text { frequency range }\end{array}$ & $\begin{array}{c}\text { Actuator } \\
\text { amplitude range }\end{array}$ & Configuration \\
\hline 0.30 & $1.610^{6}$ & {$\left[0.0^{\circ} ; 2.4^{\circ}\right]$} & {$[20 \mathrm{hz} ; 80 \mathrm{~Hz}]$} & {$\left[0.5^{\circ} ; 5.0^{\circ}\right]$} & $\begin{array}{c}\text { Aerodynamic } \\
\text { Aeroelastic }\end{array}$ \\
\hline 0.73 & $3.310^{6}$ & {$\left[0.0^{\circ} ; 2.4^{\circ}\right]$} & {$[20 \mathrm{hz} ; 80 \mathrm{~Hz}]$} & {$\left[0.5^{\circ} ; 3.0^{\circ}\right]$} & $\begin{array}{c}\text { Aerodynamic } \\
\text { Aeroelastic }\end{array}$ \\
\hline
\end{tabular}

Table 2 - experimental test matrix for wind tunnel test campaign

\subsection{Unsteady aerodynamics induced by gust}

The first part of the campaign is devoted to the study of the aerodynamic phenomena induced by gust on a fixed airfoil. 
The analyses of the unsteady pressure sensors located on the main chord are described in the following figures. In Figure 18, the grey surface covers all instantaneous pressure distribution recorded at high sampling rate while red and blue lines provides the time averaged data for subsonic flow (left graphic) and transonic flow (right graphic). As shown, the pressure levels fluctuations are significant in the leading edge area and the shock location oscillation is important for the transonic case. For this latest point, the pressure signal is modulated at the frequency of $30 \mathrm{~Hz}$ (Gust Generator Command) and the shock oscillates with a 8\% chordwise amplitude between the extreme locations. Temporal snapshot of the pressure fluctuations are given in Figure 19 for various sensors.
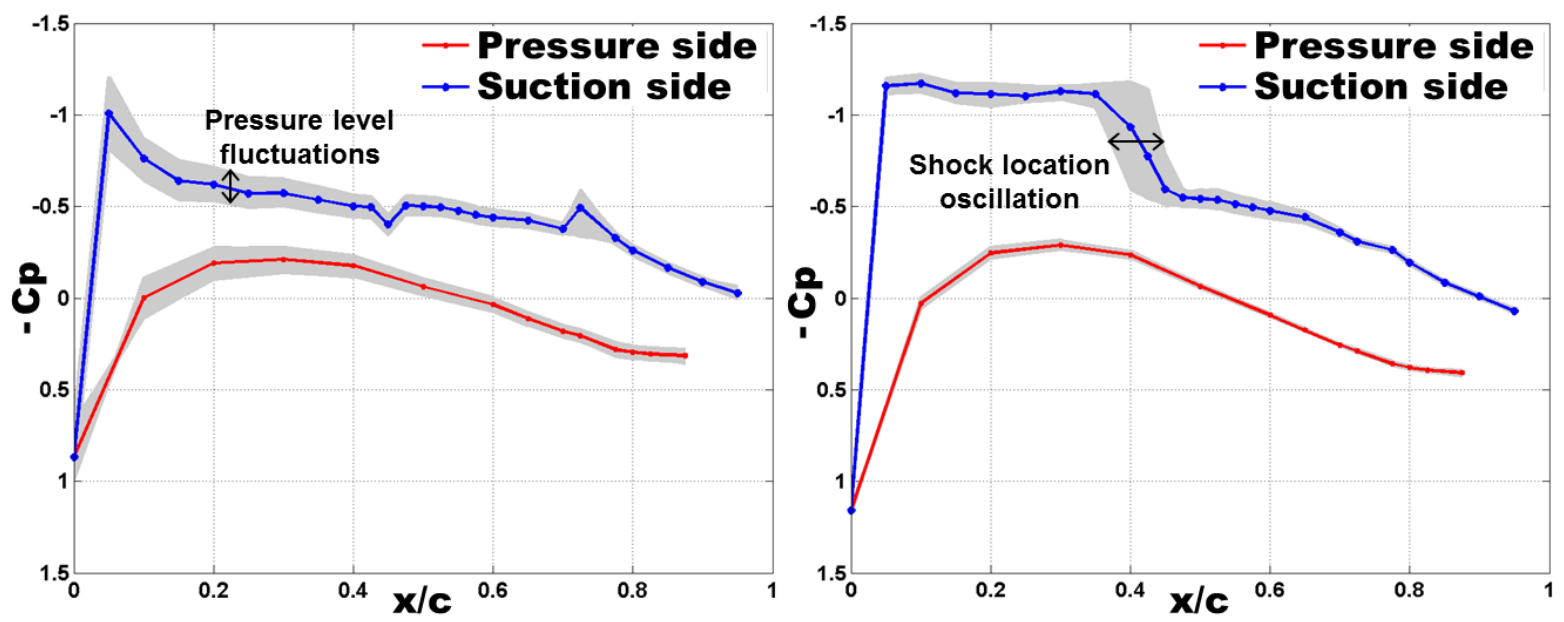

Figure 18- Instantaneous (grey) and averaged (blue and red) pressure distributions for Mach $=0.30$ (left) and Mach $=0.73$ (right), AoA $=2.0^{\circ}$, Gust Generator Amplitude $=+/-3.0^{\circ}$, Gust Generator Frequency $=30 \mathrm{~Hz}$
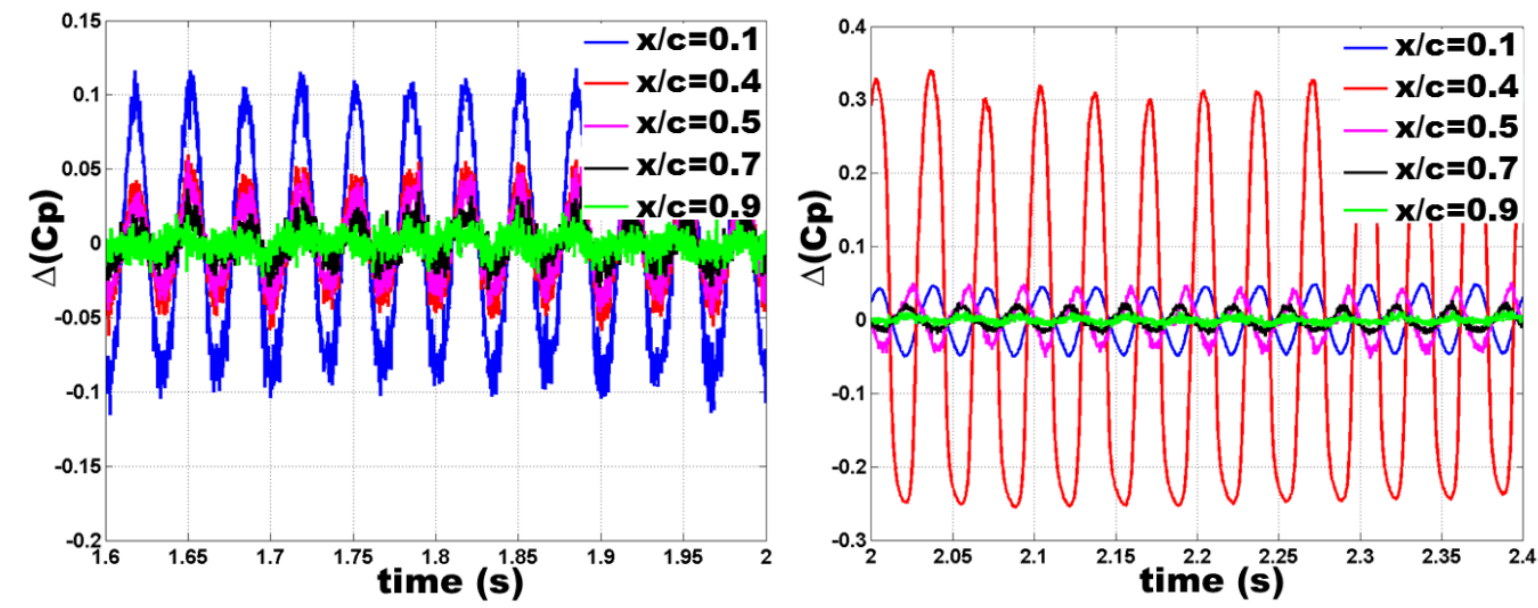

Figure 19- Temporal evolution of unsteady pressure sensors for Mach $=0.30$ (left) and Mach $=0.73$ (right), $\mathrm{AoA}=2.0^{\circ}$, Gust Generator Amplitude $=+/-3.0^{\circ}$, Gust Generator Frequency $=30 \mathrm{~Hz}$

A Fast Fourier Transform (FFT) is applied on the time pressure coefficient signals (Cp) and on the gust angle evolution (clinometric probe) considered as the reference signal. The analysis has been limited to the first harmonic corresponding to the gust excitation frequency. An example is illustrated on Figure 20 for the same test conditions than Figure 19. 

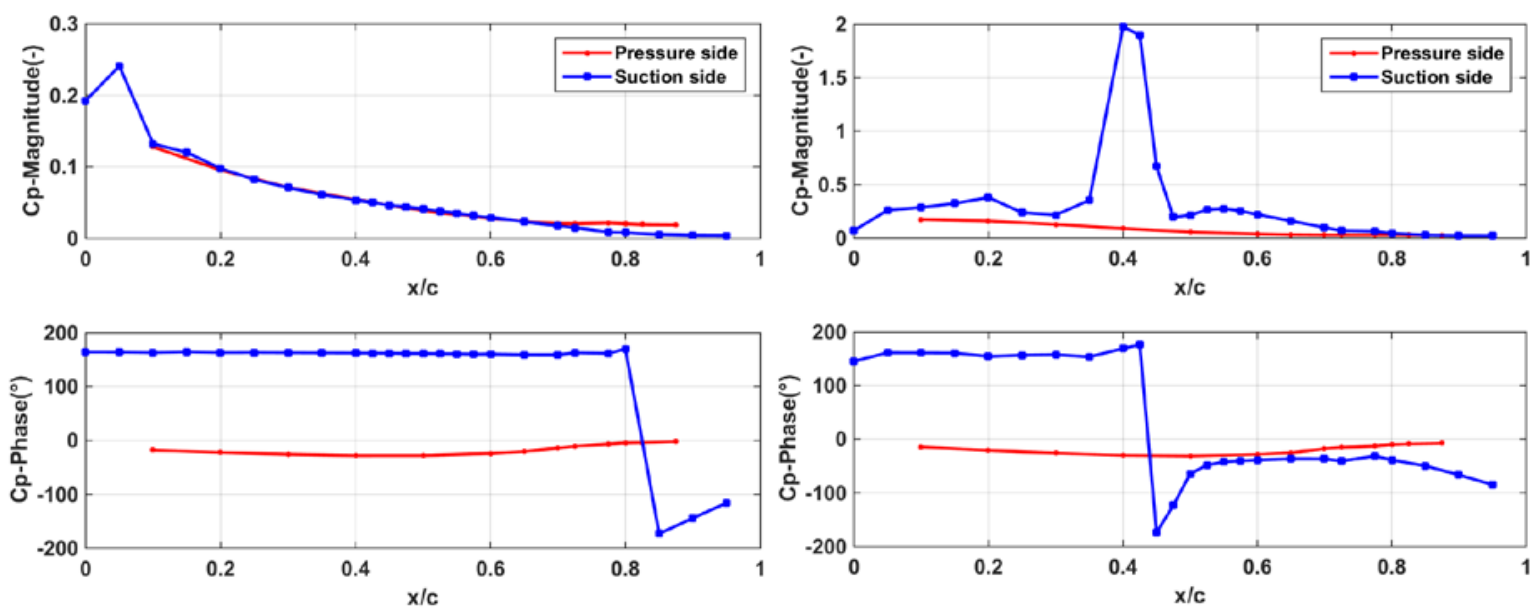

Figure 20-Distribution of First harmonic Pressure coefficient distribution for $\mathrm{M}=0.3$ (left) and 0.73 (right), $\mathrm{AoA}=2.0^{\circ}$, Gust Generator Amplitude $=+/-3.0^{\circ}$, Gust Generator Frequency $=30 \mathrm{~Hz}$

For the subsonic case, the highest magnitude of $\mathrm{Cp}$ is observed near the leading edge while the pressure responses appeared in phase with the gust perturbation. A quasi identical behavior can be observed on both suction and pressure sides. In the transonic domain, as previously described, a motion of the shock occurs which leads to large pressure variations in the vicinity of the shock and to a phase shift.

In order to estimate the global effects of impacting gusts on the aerodynamic behavior of the airfoil, the lift force is determined by integration of the measured pressure distribution. In this experiment, the use of unsteady pressure sensors located on the centerline (Figure 16) allows to estimate a corresponding "unsteady" lift force. Basically, for each sample time, the instantaneous pressure distribution is integrated over the airfoil's surface. In this case, the lift is calculated and expressed in a dimensionless form using the lift coefficient per unit chord length. Typical examples of the time signal of the lift coefficient are given in Figure 21 which clearly demonstrates the ability of generating significant unsteady loads on the airfoil driven by the frequency of the gust generator command.
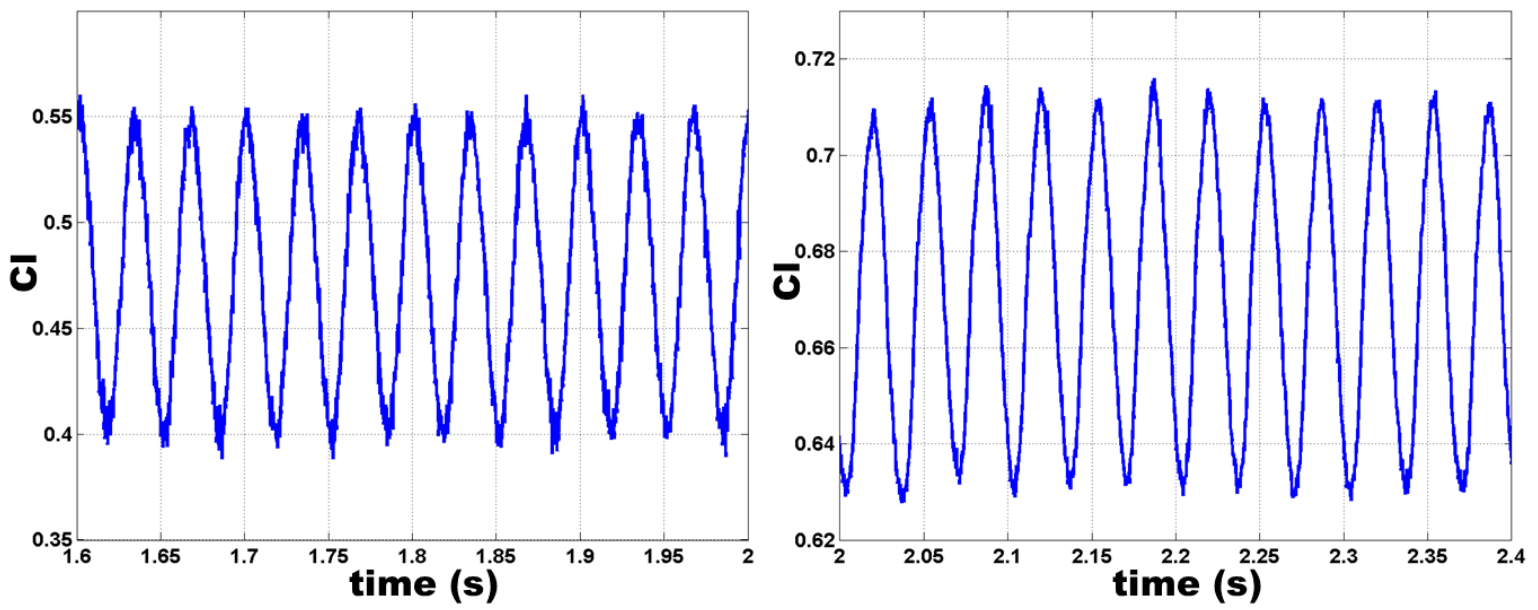

Figure 21- Temporal evolution of the lift coefficient signal for $\mathrm{M}=0.3$ (left) and 0.73 (right)

\subsection{Aeroelastic behavior in presence of gust}

For the second part of the campaign, the structural configuration is switched in "flexible case" allowing pitch and heave motion. For test conditions defined in Table 2, sine sweep signals (from $20 \mathrm{~Hz}$ to $80 \mathrm{~Hz}$ ) are used as input data to the gust generator. The gust generator 
qualification campaign has shown that for a given gust generator amplitude and set of aerodynamic conditions, the measured gust angle increases with the gust generator frequency. Thus, the motion command signal is modulated as function of the time to compensate a "frequency effect" [27] in order to generate constant gust amplitude over the wide frequency bandwidth. Figure 22 shows typical time histories and the associated transfer function between acceleration and gust probe signals for Mach number of 0.73.
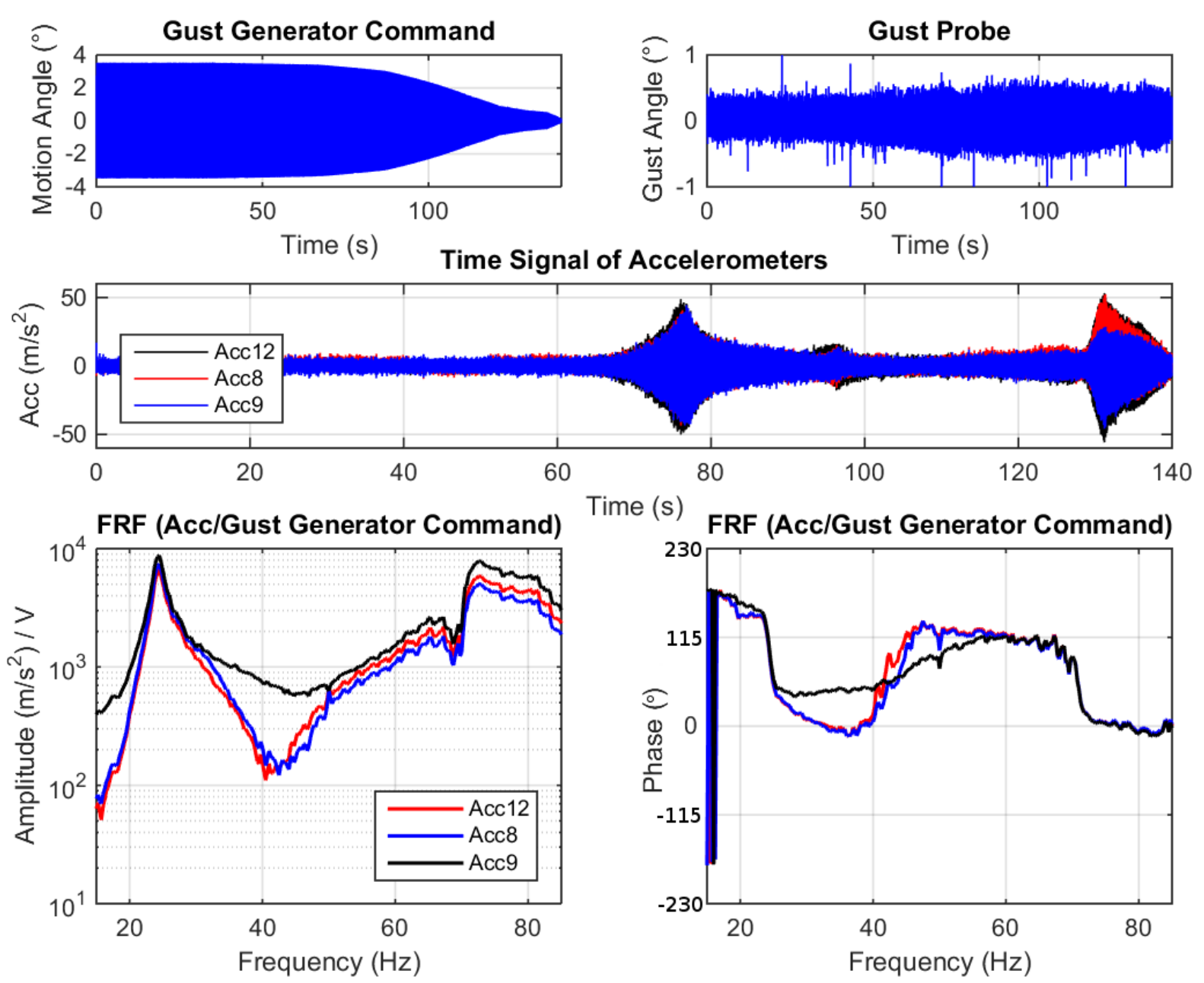

Figure 22- Time histories of motion command, gust probe and accelerometers and associated FRF - Gust generator command based on a sweep sine signal with an amplitude modulation - Tests at $\mathrm{M}=0.73$ and $\mathrm{AoA}=0^{\circ}$

\section{NUMERICAL MODEL}

11 An assessment of the gust model implemented in the code elsA (Section 2.2) is performed on one case of the experimental test matrix (Table 3).

\begin{tabular}{|c|c|c|c|c|c|c|}
\hline $\begin{array}{c}\text { Mach } \\
\text { number }\end{array}$ & $\begin{array}{c}\text { Reynolds } \\
\text { number }\end{array}$ & $\begin{array}{c}\text { Angle of } \\
\text { attack }\end{array}$ & $\begin{array}{c}\text { Actuator } \\
\text { frequency }\end{array}$ & $\begin{array}{c}\text { Actuator } \\
\text { amplitude }\end{array}$ & $\begin{array}{c}\text { Gust angle } \\
\text { (embedded probe) }\end{array}$ & Gust length \\
\hline 0.73 & $3.310^{6}$ & $2.0^{\circ}$ & $25 \mathrm{~Hz}$ & $3.0^{\circ}$ & $0.21^{\circ}$ & 38 airfoil chords \\
\hline \multicolumn{6}{|c}{ Table 3-numerical test case }
\end{tabular}

\subsection{Computation process and case definition}

15 In order to perform a computation as close as possible to an industrial modeling, the Field Velocity Method must be validated with farfield boundary conditions. A validation process is 
1 defined in order to move from experimental results obtained in the wind tunnel with wall 2 boundaries to numerical results computed with farfield boundaries (Figure 23).

3 First, a part of the wind tunnel is modeled taking into account the gust generator, the airfoil 4 and the upper and lower wall deformations. This modelling aims at validating the elsA 5 software as close as possible to the experimental setup by comparing pressure field around the 6 airfoil.

7 Second, the airfoil is modeled with farfield conditions (so without gust generator and wind 8 tunnel walls) and the Field Velocity Method.

9 For both simulations, computations are split in two steps:

- A steady computation is performed where physical parameters (angle of attack, inlet and outlet pressure for the wind tunnel modelling and Mach number for farfield modeling) are tuned in order to fit the pressure distribution around the airfoil;

For the unsteady cases, the same post-processing based on Fast Fourier Transform is applied to the experimental and numerical pressure coefficient and acceleration signals in order to perform consistent and reliable comparison.

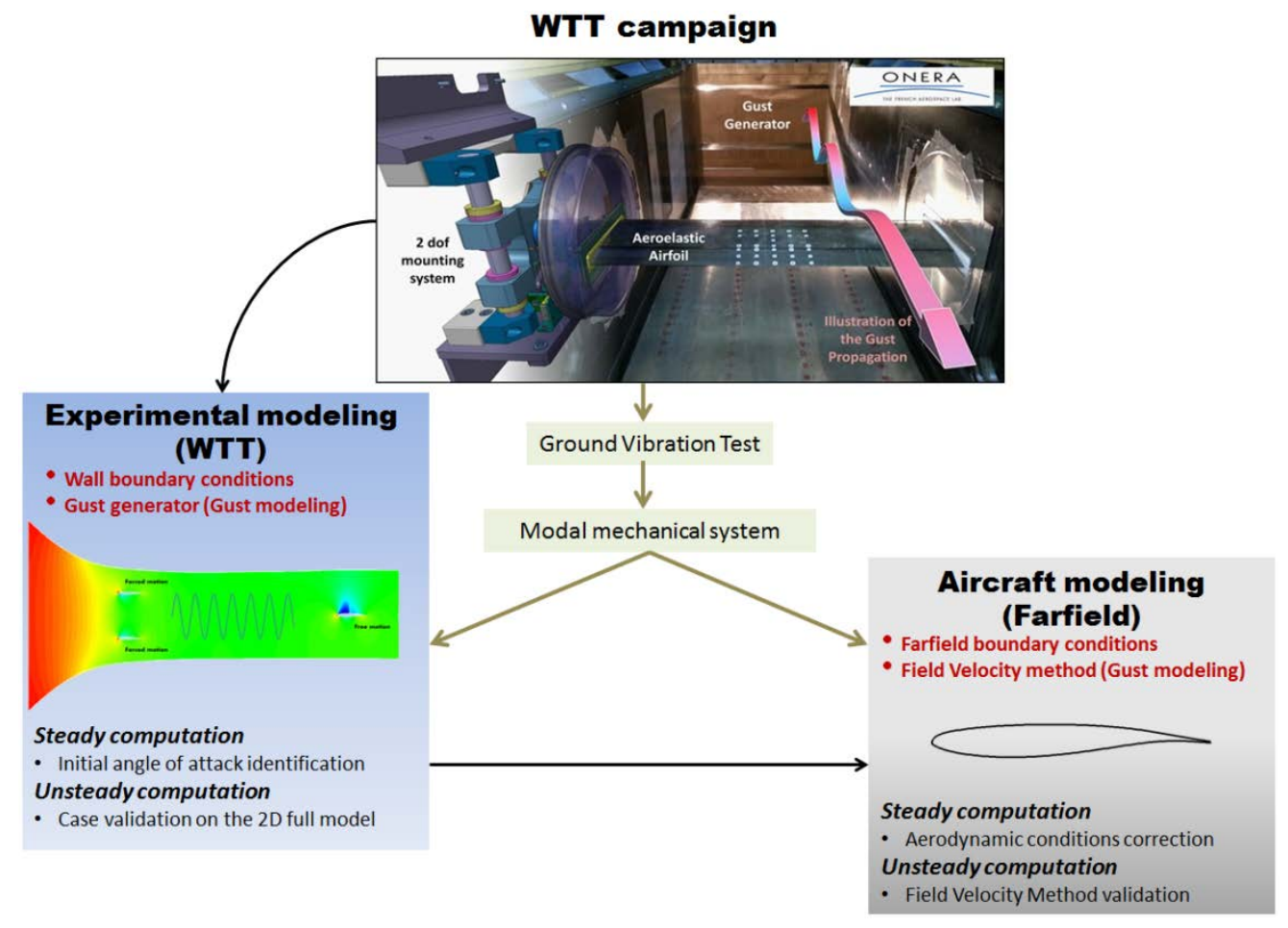

- An unsteady computation is performed from the steady state in order to assess the pressure and acceleration fluctuations around the airfoil.

Figure 23- Numerical process for validation

\subsection{Numerical model}

From the experimental results:

- The aerodynamic phenomena around the centerline can be considered as two dimensional thanks to the analyze of pressure sensors located in the spanwise direction (Figure 16);

- The gust generator qualification has demonstrated its ability to generate a reproducible and significant sine gust field (Figure 7); 

frequency $(77.2 \mathrm{~Hz})$.

From a modeling point a view:

- The FVM models the gust with a sine signal; conditions (Figure 25).

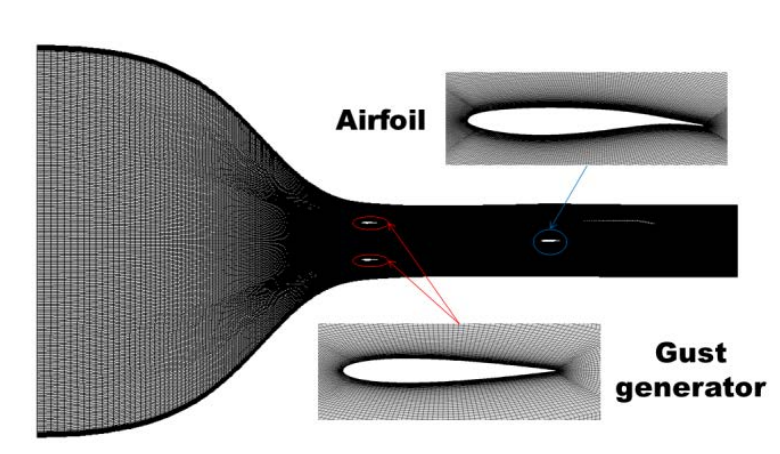

Figure 24- Wind tunnel mesh

- The aeroelastic model characterization has demonstrated that the two rigid modes (heave and pitch) are located in a low frequency range $(24.7 \mathrm{~Hz}$ and $30.1 \mathrm{~Hz}$ respectively) while the first flexible mode (bending mode) is located at a higher

- The results analysis allows considering computations with a 2D-model;

- As the bending mode is located far from the gust frequency $(25 \mathrm{~Hz})$, only the heave and pitch modes are taken into account in the structural model.

Two models are built: one for the WTT conditions (Figure 24) and one for the farfield

The wind tunnel is modeled in 2D. It takes into account the two wings of the gust generator, the OAT15 airfoil and the adapted upper and lower walls of the wind tunnel. In order to avoid any numerical approximation due to no-match or Chimera conditions, all block interfaces of the structured mesh are matched. A condition of adherent wall is imposed on each wall of the domain (upper and lower walls, airfoils). These constraints lead to a first mesh built with 316000 cells in the domain, 192 nodes on each side of the OAT15 airfoil and 100 nodes on each side of each gust generator. From this mesh, a second one is built by applying a refinement by a factor 2 along each direction. It leads to a mesh with 1.25 million of cells.

The second model consists of the same OAT15 airfoil with conditions of adherent wall on the airfoil and farfield conditions elsewhere (the wind tunnel is not modelled). A C-mesh is built around the airfoil leading to a mesh of 99000 cells with 207 nodes on each side of the airfoil. From this mesh, two refined meshes are built by applying, respectively, a refinement by a factor 2 and 3 along each direction. It leads to meshes with 396000 cells and 891000 cells.

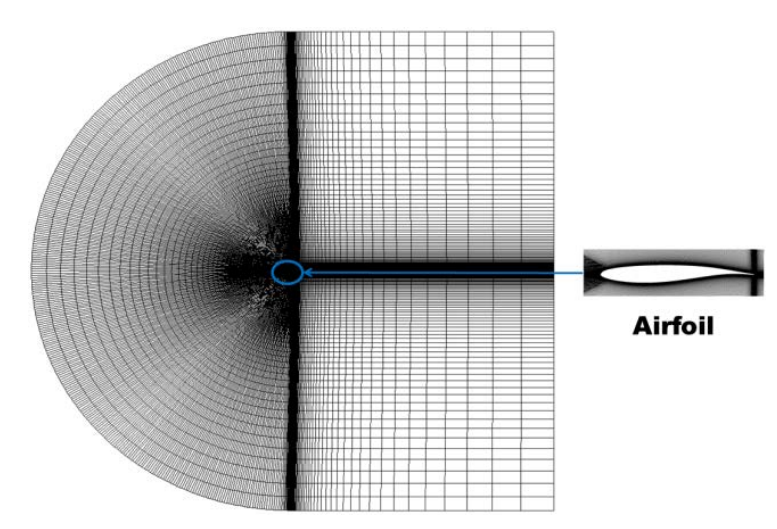

Figure 25- Farfield mesh

25 The fluid is assumed to be a viscous perfect gas. The Wilcox $(\mathrm{k}, \omega)$ turbulence model is used 26 with the Zheng limiter.

27 The modal parameters (mass, damping ratio, stiffness and mode shape) obtained from the 28 experimental structural characterization are used in the structural solver instead of extracting 29 them from a finite element model. Especially, the experimental mode shapes (Figure 13) are mapped onto the aerodynamic grid using the technique described in 2.2-Data transfer. 


\subsection{Initial angle of attack identification}

\subsubsection{Steady computation}

The aerodynamic flow is driven by the inlet and outlet pressure of the computational domain. As only a part of the wind tunnel is modeled, the inlet and outlet pressures of the computational domain are assumed unknown. Experimentally, a probe located after the throat drives the aerodynamics conditions (Mach and static pressure) in the wind tunnel. So, both pressures are tuned until the requested Mach and static pressure corresponding to the probe measurement are found.

In fact, this approach is not sufficient to correctly reproduce the pressure field around the airfoil. A given steady flow condition imposes a static deflection on the airfoil due to the aeroelastic behavior. It leads to a modification of the initial angle of attack. The numerical steady deformation is not properly computed from the initial angle of attack in order to match the steady pressure distribution.

As the steady deformation has not been measured, the steady flow cannot be computed directly on the steady position. Therefore, the initial angle of attack is assumed unknown. The shock location is used in order to find the corresponding initial angle of attack thanks to a pressure tap and corresponding grid cell located on the shock.

The initial angle of attack, combined to the inlet and outlet pressures in the wind tunnel, are tuned until the convergence of the target parameters (Mach and static pressure, shock location) to experimental values (Figure 26). The problem is formulated with cost functions and is solved with a Newton-Raphson algorithm.

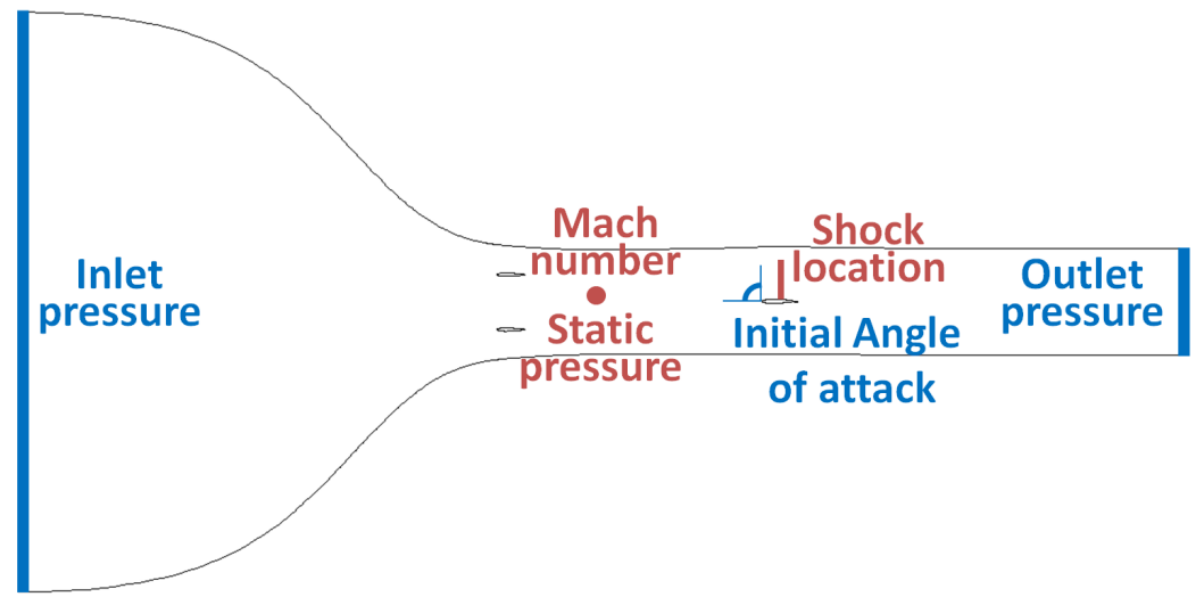

Figure 26: initial angle of attack identification: unknown parameters (blue) and target parameters (red)

The identification algorithm runs until a relative convergence less than $10^{-10}$ on the three target parameters is achieved. A mesh sensitivity analysis is performed on two mesh refinements. The mesh sensitivity analysis shows that the two levels of mesh refinement give the same initial angle of attack $\left(1.43^{\circ}\right)$ and pressure distribution (Figure 27). Comparing numerical and experimental data, a difference appears at the shock position on the upper surface. Numerical results under-estimate the pressure on the upper surface while on the lower surface, the pressure is over-estimated. 


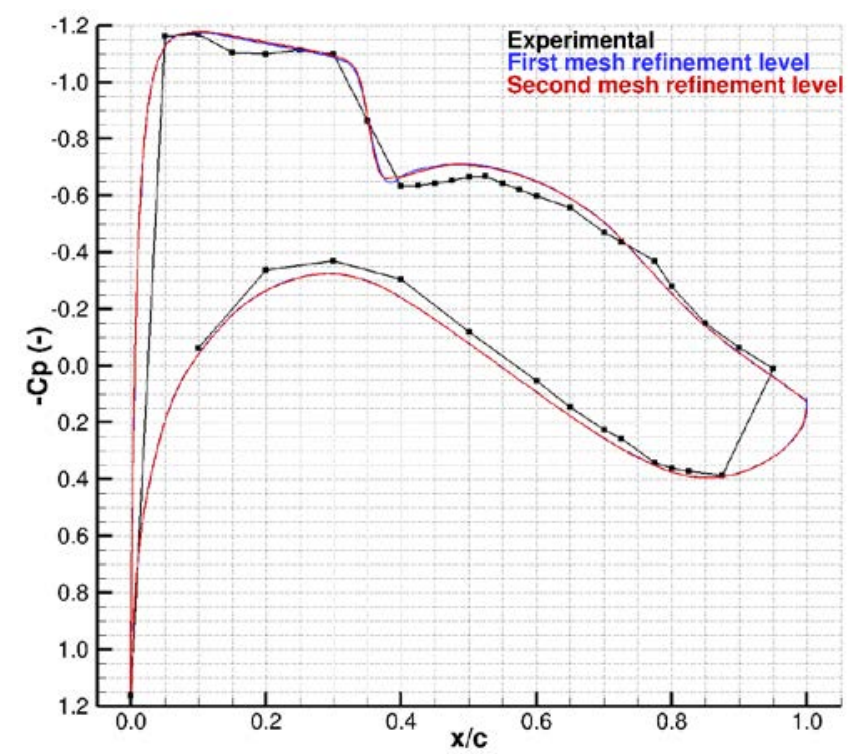

Figure 27: Pressure coefficient distribution around the OAT15 airfoil (wind tunnel modeling)

\subsubsection{Unsteady computation}

For the unsteady computation with wind tunnel modeling, a mesh sensitivity study is performed on two levels. For both meshes, time step sensitivity is studied with 4 levels of refinement. The gust sine signal is discretized with 16, 32, 64 and 128 iterations per period respectively.

First of all, space and time sensitivities are evaluated on the gust probe location. The clinometric probe is located $0.08 \mathrm{~m}$ ahead of the leading edge. The gust velocity vector is post-processed at each time step in the closest cell to the experimental location in order to obtain an unsteady gust angle. Due to the aeroelastic deformation, the clinometric probe location changes during the simulation. In order to have an accurate assessment of the gust velocity, it is assumed that the clinometric probe has a rigid motion. A Fourier analysis is applied on the gust velocity in order to get the magnitude corresponding to the frequency of the command signal driving the gust generator airfoils motions. For the selected spatial and time resolution, a further refinement has not shown any influence on the gust velocity magnitude. The numerical gust magnitude $\left(0.27^{\circ}\right)$ is over-estimated in comparison with the experimental value $\left(0.21^{\circ}\right)$.

Based on the numerical sensitivity analysis, the comparison between experimental and numerical results is performed on the second mesh level with 64 iterations per periods.

For both aerodynamic (pressure coefficient around the airfoil) and structural (acceleration) results, a transfer function is computed using the gust velocity as reference. The same analysis process is applied to experimental and numerical results.

From an aerodynamic point of view, the main phenomena are caught (Figure 28). Some differences appear around the shock, the maximum magnitude is more important for the computation.

From a structural point of view, the main phenomena are also caught. For the acceleration magnitude (left graphic of Figure 29), the main difference appears close to the leading edge with an over-estimation. The airfoil is equipped with control surface, the hinge being attached at $75 \%$ of the chord for control load alleviation purposes. This activity is not a part of this work and the flap is assumed rigid for the current work. But a small flap disturbance or local unsteady deformations could explain the difference close to the trailing edge. A difference 
1 appears also on the phase (right graphic of Figure 29) with the same evolution than for the 2 magnitude close to the hinge.
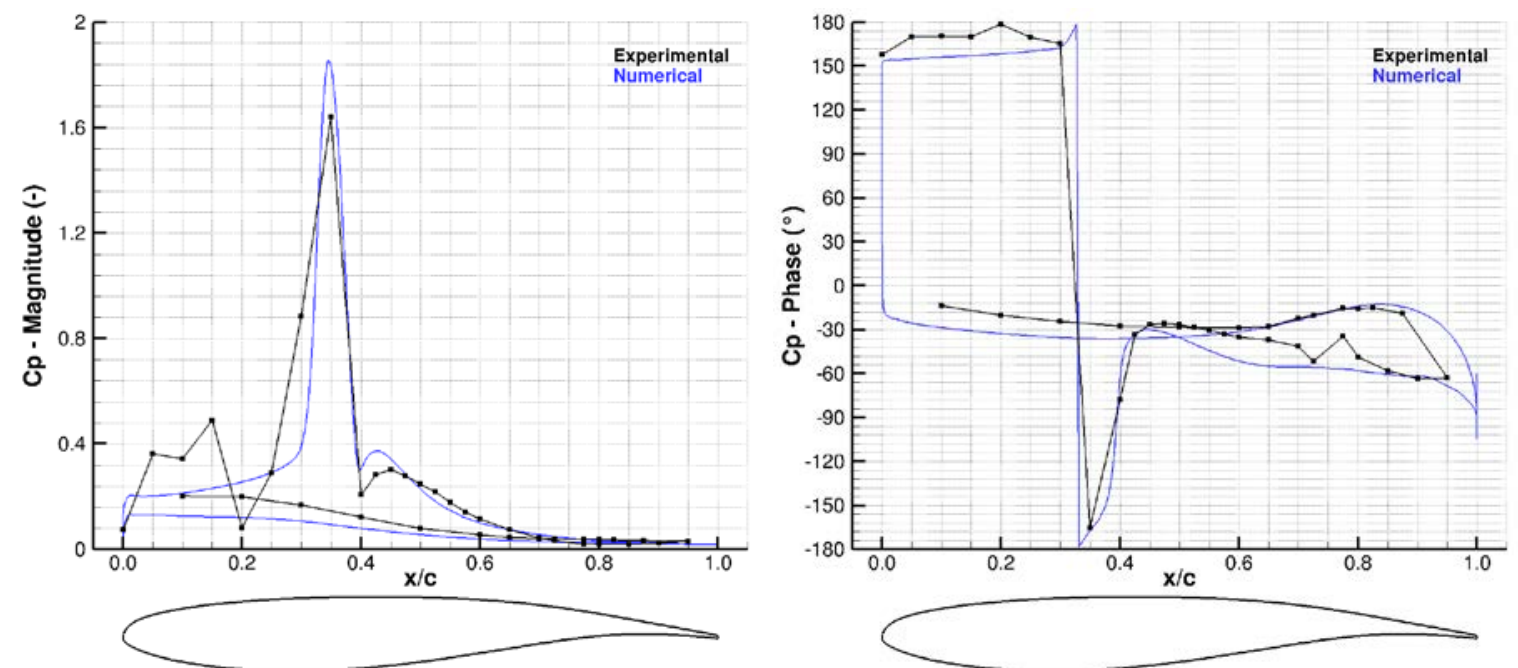

Figure 28 : Aerodynamics - Comparison of numerical and experimental results - Pressure coefficient magnitude (left) and phase (right) distribution around the OAT15 airfoil (wind tunnel modeling)
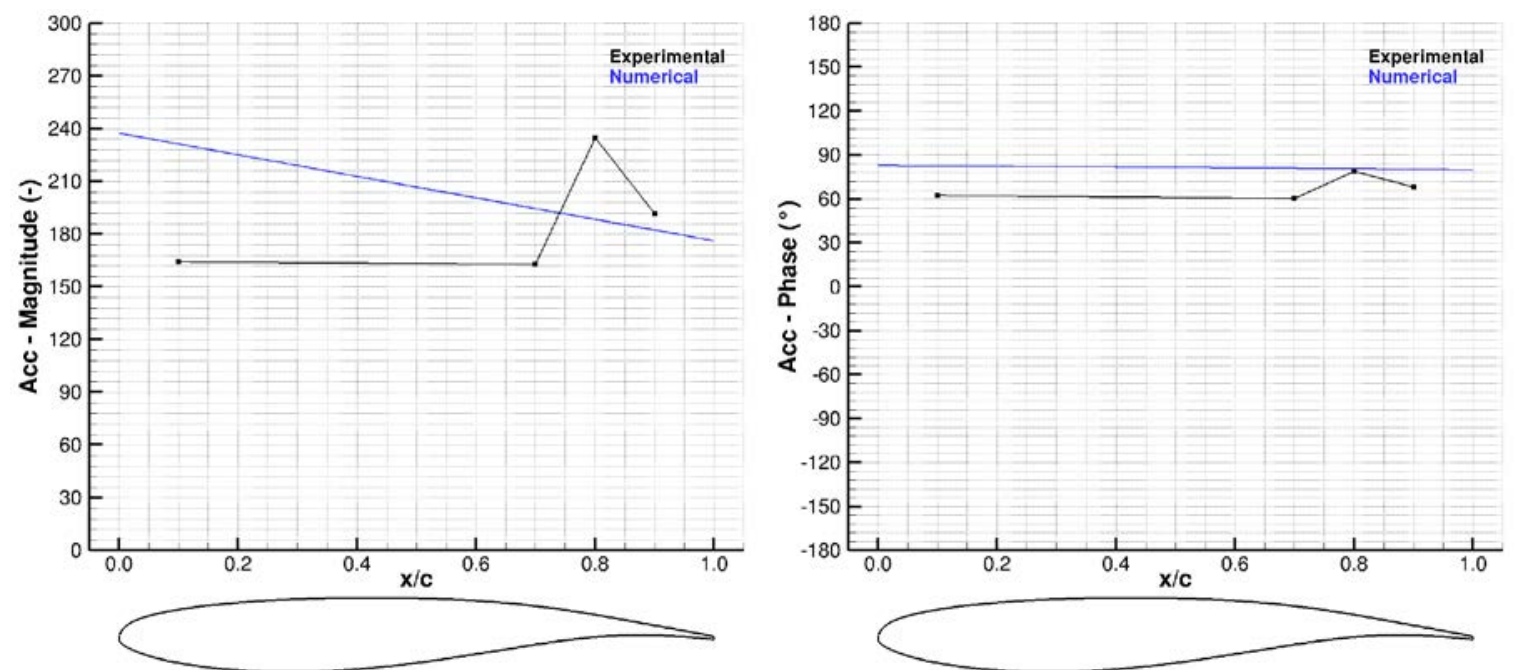

Figure 29: Structure - Comparison of numerical and experimental results -acceleration magnitude (left) and phase (right) distribution around the OAT15 airfoil (wind tunnel modeling)

\subsection{Farfield modeling}

\subsubsection{Steady computation}

The same aerodynamic conditions found during the wind tunnel modeling are imposed on the farfield modeling (initial angle of attack). A correction on the Mach number has to be added in order to take into account the farfield conditions. The Mach number is adapted based on the shock location given by the pressure sensor located on the airfoil and the initial angle of attack assessed during the first computation step. The identification algorithm runs until a relative convergence on the pressure sensor is reached. The mesh sensitivity analysis is performed on three mesh refinements. The mesh sensitivity analysis shows that the three levels of mesh refinement give the same Mach number (0.72) and pressure distribution (Figure 30). Comparing the numerical and experimental data, the pressure distribution is well reproduced except behind the shock location. As for the wind tunnel modeling, the pressure distribution is underestimated by the numerical simulation. The pressure distribution over the 
1 lower surface is better predicted than in the case of the wind tunnel modeling. The three levels

2 of mesh refinement give the same static pressure distribution around the airfoil.

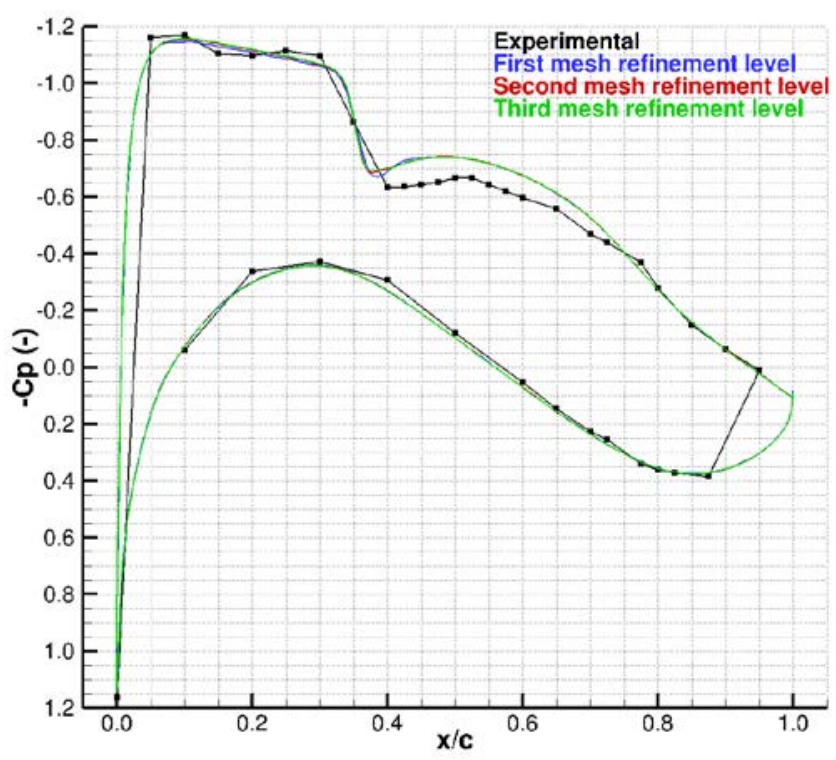

Figure 30: Pressure coefficient distribution around the OAT15 airfoil (Farfield modeling)

\subsubsection{Unsteady computation}

As for the steady computation, the mesh sensitivity study for the gust response simulation is performed on three grid refinement levels. For all meshes, time sensitivity is studied on 4 levels. The gust sine signal is discretized with 16, 32, 64 and 128 iterations per period respectively. The gust magnitude at the clinometric probe location depends on the magnitude imposed to the Field Velocity Method. Due to a relative linear behavior between the gust value imposed in the FVM and the values computed at the gust location, two computations are performed in order to assess the magnitude to be imposed using the Field Velocity Method. From the sensitivity analysis, the second grid level of refinement with 64 iterations per period is selected for comparison with the experimental data.

The aerodynamics is reproduced with more difficulty than with the wind tunnel modeling (Figure 31). On the one hand, the magnitude peak on the pressure distribution is well caught, due to the tuning of the FVM model. On other hand, the magnitude after the shock position and on the lower surface is less accurately predicted. A large difference appears on the phase around the trailing edge. The previous wind tunnel modeling leads to a better prediction of the phase.

The structural behavior is better reproduced with the farfield condition than with the wind tunnel modeling (Figure 32). With the farfield modeling, the magnitude is closer to the experimental result near the leading edge and only a small difference appears near the trailing edge. The phase is correctly predicted. The structural acceleration is also better predicted by the farfield modeling. The wind tunnel modeling gives only better results for the pressure coefficient distribution.

As the same structural data and solver are used in both cases, the difference on aeroelastic results comes from the aerodynamics. For the boundary conditions modeling, the wind tunnel walls are deformed in order to reduce their impact on the flow around the airfoil. It leads to compute the steady pressure distribution with a different accuracy depending on the model considered. The pressure coefficient distribution is under-estimated for the wind tunnel modelling on the upper surface after the shock location and is over-estimated on the lower surface. For the farfield modeling, the pressure distribution is under-estimated more largely 
after the shock location but is better predicted on the lower surface. Another explanation for the difference on the aeroelastic results could be linked to the gust amplitude. Its value is indeed adjusted for the farfield modeling in order to have the same maximum amplitude at the clinometric probe location. Such an adjustment is not done for the wind tunnel modeling.
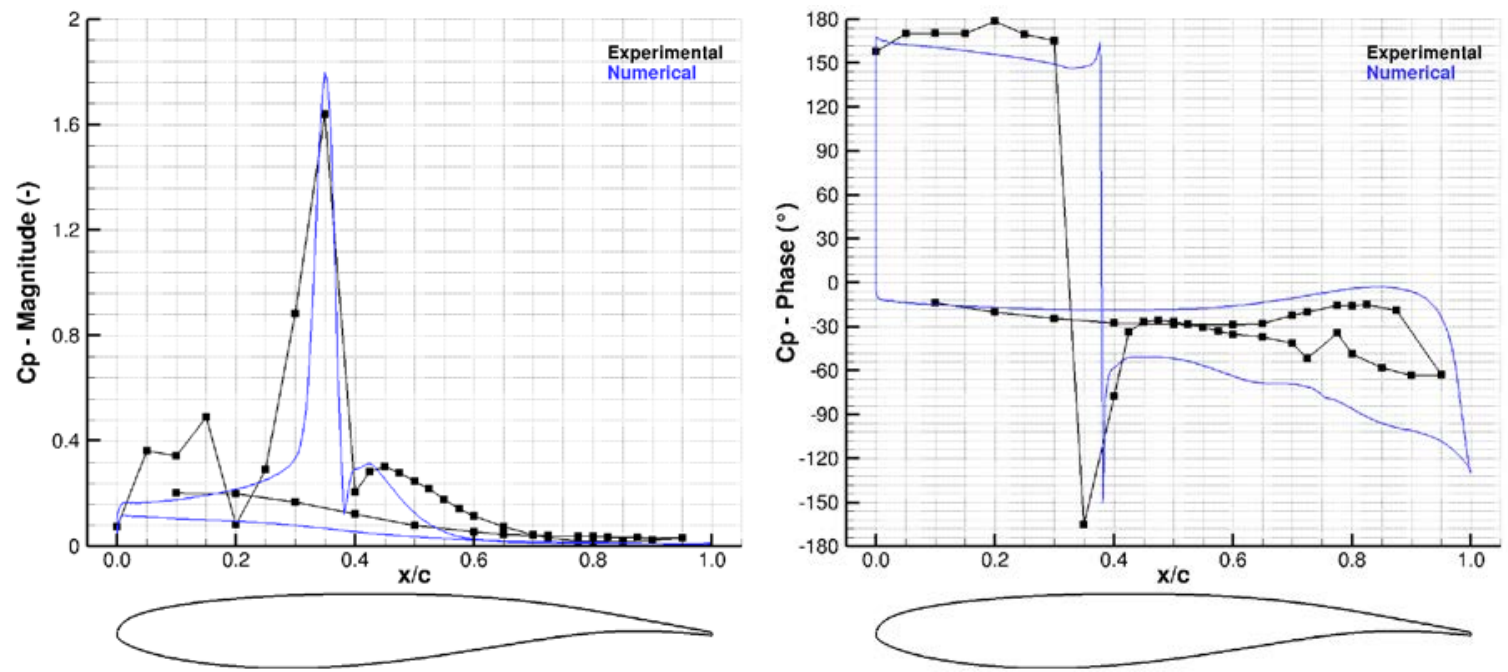

Figure 31: Aerodynamics - Comparison of numerical and experimental results - Magnitude and phase distribution around the OAT15 airfoil (Farfield modeling)
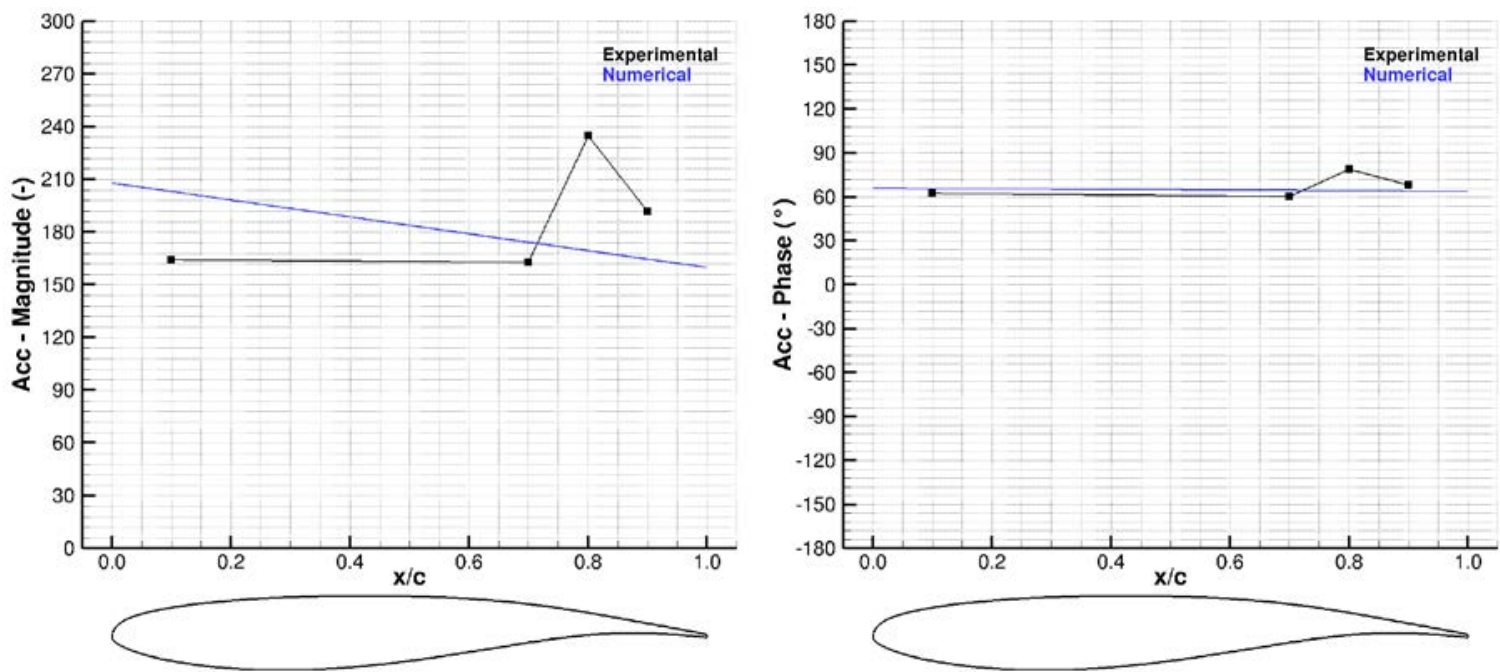

Figure 32: Structure - Comparison of numerical and experimental results - Magnitude (abs) and phase distribution around the OAT15 airfoil (Farfield modeling)

\section{CONCLUSIONS}

A new experimental setup has been developed in order to investigate a gust encountering an aeroelastic model. This model has been designed using high fidelity computations. WTT campaigns have been achieved in the ONERA S3Ch wind tunnel facility. First, the gust generator capabilities relatively to different aerodynamic condition have been efficiently and parametrically qualified. The database analyses have led to the conclusion that the gust generator fulfilled the requirements specifications: this device has allowed to generate a cylindrical gust field in wind tunnel environment in a reproducible and controlled way. Then, the experimental setup based on a 2 dof aeroelastic airfoil demonstrated its capability to describe unsteady aerodynamics and aeroelasticity in presence of a gust. The achieved tests have provided an experimental database with parametric variations of aerodynamic conditions (Mach number and angle of attack) and gust excitation parameters. 
A numerical validation of harmonic gust excitation has been performed with the high fidelity code elsA for one case of the experimental database. A sinusoidal gust perturbation close to the modal frequency of the first mode of the model (heave mode) has been chosen as study case. A sensitivity analysis in space and time has been performed and allowed the selection of the appropriate refinement level. Firstly, the modelling of the full wind tunnel and gust generator has allowed to validate the numerical approach. Secondly, the capabilities of the Field Velocity Method have been assessed with farfield boundary conditions. Both simulations have demonstrated their capabilities to describe the aerodynamic and structural phenomena.

\section{REFERENCES}

[1] Albano, E., Rodden, W. P., A Doublet-Lattice Method for Calculating Lift Distributions on Oscillating Surfaces in Subsonic Flows, AIAA Journal , 7(2):279-285, 1969

[2] Valente, C., Wales, C., Jones, D., Gaitonde, A., Cooper, J. E., Lemmens, Y., A DoubletLattice Method Correction Approach for High Fidelity Gust Loads Analysis, 58th AIAA/ASCE/AHS/ASC Structures, Structural Dynamics, and Materials Conference. Grapevine, Texas, January 2017

[3] Raveh, D.E., CFD-Based Models of aerodynamic gust response, Journal of Aircraft, Vol 44, No 3, May-June 2007

[4] Heinrich R., Simulation of Interaction of Aircraft and Gust Using the TAU-Code, In: Dillmann A., Heller G., Krämer E., Kreplin HP., Nitsche W., Rist U. (eds) New Results in Numerical and Experimental Fluid Mechanics IX. Notes on Numerical Fluid Mechanics and Multidisciplinary Design, Springer, Cham, vol 124, 2014

[5] Liauzun, C., Aeroelastic response to gust using CFD techniques, Proceedings of 3rd Joint US-European Fluids Engineering Summer Meeting and 8th International Conference on Nanochannels, Microchannels, and Minichannels, FEDSM2010ICNMM2010, Montreal, Canada, August 2010

[6] Tang, D.M., Cizmas, P.G.A., Dowell E.H., Experiments and Analysis for a gust generator in a wind tunnel, Journal of Aircraft, Vol. 33, N¹, 1996

[7] Ricci, S. and Scotti, A., Wind Tunnel Testing of an Active Controlled Wing under Gust Excitation, 49th AIAA/ASME/ASCE/AHS/ASC Structures, Structural Dynamics and Material Conference. Schaumburg, IL, USA, April 2008

[8] Lancelot, P., Sodja, J., Werter, N., De Breuker, R., Design and Testing of a Low Subsonic Wind Tunnel Gust Generator, International Forum on Aeroelasticity and Structural Dynamics, Saint Petersburg, Russia, June 2015

[9] Silva, W. A., Vartio E. , Shimko, A., Kvaternik, R.G., Eure, K.W., Scott, R.C., Development of Aeroservoelastic Analytical Models and Gust Load Alleviation Control Laws of a SensorCraft Wind-Tunnel Model Using Measured Data IFASD 2007, International Forum on Aeroelasticity and Structural Dynamics, Stockholm, Sweden, June 2007

[10] Neumann, J., Mai, H., Gust Response : Simulation of an aeroelastic experiment by a fluid-structure interaction method, Journal of Fluilds and Structures, 38 (2013), pp290302

[11] Girodroux-Lavigne, P., Progress in steady/unsteady fluid-structure coupling with Navier-Stokes equations, International Forum on Aeroelasticity and Structural Dynamics, Munich, Germany, June 2005 
[12] Dugeai, A., Aeroelastic Developments in the elsA Code and Unsteady RANS Applications, International Forum on Aeroelasticity and Structural Dynamics, Munich, Germany, June 2005

[13] Girodroux-Lavigne, P., Recent Navier-Stokes aeroelastic simulations using the elsA code for aircraft applications, International Forum on Aeroelasticity and Structural Dynamics, Stockholm, Sweden, June 2007

[14] Cambier, L., Heib, S., Plot, S. , The Onera elsA CFD software : input from research and feedback from industry, Mechanics \& Industry, 14(3): 159-174, 2013

[15] Gazaix, M., Jolles, A., Lazareff, M., The elsA Object-Oriented Computational tool for industrial applications, 23rd Congress of ICAS, Toronto, Canada, September 2002

[16] Heinrich, R., Reimer, L., Comparison of different approaches for gust modeling in the CFD code Tau, International Forum on Aeroelasticity and Structural Dynamics, Bristol, Great Britain, June 2013

[17] Sitaraman, J., Iyengar, V. S., and Baeder, J. D., On field velocity approach and geometric conservation law for unsteady flow simulations, 16th AIAA Computational Fluid Dynamics Conference, Orlando FL, June 2003

[18] Huvelin, F., Girodroux-Lavigne, P., Blondeau, C., High fidelity numerical simulations for gust response analysis, International Forum on Aeroelasticity and Structural Dynamics, Bristol, Great Britain, June 2013

[19] Wales, C., Cook, R.G., Jones, D.P., Gaitonde, A.L., Comparison of aerodynamic models for 1-cosine gust loads prediction, International Forum on Aeroelasticity and Structural Dynamics, Como, Italy, June 2017

[20] Huntley,S.J., Jones,D. and Gaitonde, A., Aeroelastic Gust Response of an Aircraft Using a Prescribed Velocity Method in Viscous Flows, 23rd AIAA Computational Fluid Dynamics Conference, Denver USA, June 2017

[21] Harder, R. L. and Desmarais, R. N, Interpolation using surface splines, Journal of Aircraft, Vol. 9, No. 2, pp. 189-191, 1972

[22] Delbove, J., Contribution aux outils de simulation aéroélastique des aéronefs : prédiction du flottement et déformation statique des voilures, Thèse de doctorat Dynamique des fluides Toulouse, 2005ESAE0006, ENSAE, 2005

[23] Brion, V., Lepage, A., Amosse, Y., Soulevant, D., Senecat, P., Abart, J.C., Paillart, P., Generation of vertical gusts in a transonic wind tunnel, Experiments in Fluids, Volume 56, Issue 7, July 2015

[24] Rodde, A.M., and Archambaud, J.P. , OAT15A Airfoil Data, AGARD ADVISORY REPORT N 303 : “ A selection of Experimental Test Cases for the Validation of CFD Codes”

[25] Farmer, M.G., A two-degree of freedom mount system with low damping for testing rigid wings at different angles of attack, NASA-TM-83302 Langley Research Center, 1982

[26] Jacquin, L., Molton, P., Deck, S., Maury, B., Soulevant, D., An Experimental Study of Shock Oscillation over a Transonic Supercritical Profile, 35th AIAA Fluid Dynamics Conference and Exhibit, Toronto, Canada, June 2005

[27] Lepage, A, Amosse Y., Le Bihan D., Poussot-Vassal C., Brion V., Rantet E., A complete experimental investigation of gust load : from generation to active control, International Forum on Aeroelasticity and Structural Dynamics, Saint Petersburg, Russia, June 2015 